\title{
Combined polyhydroxyalkanoates (PHA) and 1,3-propanediol production from crude glycerol: Selective conversion of volatile fatty acids into PHA by mixed microbial consortia
}

Burniol Figols, Anna; Varrone, Cristiano; Le, Simone Balzer; Daugaard, Anders Egede; Skiadas, loannis V.; Gavala, Hariklia N.

Published in:

Water Research

Link to article, DOI:

10.1016/j.watres.2018.02.029

Publication date:

2018

Document Version

Peer reviewed version

Link back to DTU Orbit

Citation (APA):

Burniol Figols, A., Varrone, C., Le, S. B., Daugaard, A. E., Skiadas, I. V., \& Gavala, H. N. (2018). Combined polyhydroxyalkanoates (PHA) and 1,3-propanediol production from crude glycerol: Selective conversion of volatile fatty acids into PHA by mixed microbial consortia. Water Research, 136, 180-191.

https://doi.org/10.1016/j.watres.2018.02.029

\section{General rights}

Copyright and moral rights for the publications made accessible in the public portal are retained by the authors and/or other copyright owners and it is a condition of accessing publications that users recognise and abide by the legal requirements associated with these rights.

- Users may download and print one copy of any publication from the public portal for the purpose of private study or research.

- You may not further distribute the material or use it for any profit-making activity or commercial gain

- You may freely distribute the URL identifying the publication in the public portal 
Research

Manuscript Number: WR41924R1

Title: Combined polyhydroxyalkanoates (PHA) and 1,3-propanediol production from crude glycerol: Selective conversion of volatile fatty acids into PHA by mixed microbial consortia

Article Type: Research Paper

Keywords: Polyhydroxyalkanoates; PHA; crude glycerol; mixed microbial consortia; 1,3-propanediol; enrichment

Corresponding Author: Dr. Hariklia Gavala, PhD

Corresponding Author's Institution: The Technical University of Denmark

First Author: Anna Burniol-Figols

Order of Authors: Anna Burniol-Figols; Cristiano Varrone; Simone B Le; Anders E Daugaard; Ioannis V Skiadas; Hariklia N Gavala

Abstract: Crude glycerol is an important by-product of the biodiesel industry, which can be converted into volatile fatty acids (VFA) and/or 1,3-propanediol (1,3-PDO) by fermentation. In this study, a selective conversion of VFA to polyhydroxyalkanoates (PHA) was attained while leaving 1,3-PDO in the supernatant by means of mixed microbial consortia selection strategies. The process showed highly reproducible results in terms of PHA yield, $0.99 \pm 0.07 \mathrm{Cmol} \mathrm{PHA} / \mathrm{Cmol} \mathrm{S}(0.84 \mathrm{~g} \mathrm{COD} \mathrm{PHA} / \mathrm{g} \mathrm{COD} \mathrm{S})$, PHA content $(76 \pm 3.1 \mathrm{~g}$ PHA/100 g TSS) and 1,3-PDO recovery (99 $\pm 2.1 \%)$. The combined process had an ultimate yield from crude glycerol of $0.19 \mathrm{~g}$ COD PHA and 0.42 g COD 1,3-PDO per $g$ of input COD. The novel enrichment strategy applied for selectively transforming fermentation by-products into a high value product (PHA) demonstrates the significance of the enrichment process for targeting specific bio-transformations and could be potentially proved valuable for other biotechnological applications as well. 
$1 \quad$ Title

2 Combined polyhydroxyalkanoates (PHA) and 1,3-propanediol production from crude glycerol:

3 Selective conversion of volatile fatty acids into PHA by mixed microbial consortia

\section{Authors}

$5 \quad$ Anna Burniol-Figols ${ }^{a}$, Cristiano Varrone ${ }^{a, c}$, Simone Balzer Le ${ }^{b}$, Anders Egede Daugaard ${ }^{a}$, loannis

6 V. Skiadas ${ }^{a}$ and Hariklia N. Gavala ${ }^{a^{*}}$.

\section{Affiliations}

$8{ }^{a}$ Technical University of Denmark (DTU), Dept. of Chemical and Biochemical Engineering,

9 Søltofts Plads, Building 229, 2800 Kgs. Lyngby (Denmark)

${ }^{\mathrm{b}}$ SINTEF, Materials and Chemistry, Dept. of Biotechnology and Nanomedicine, Postboks 4760

11 Torgarden, 7465 Trondheim (Norway)

$12{ }^{\mathrm{c}}$ new address: Aalborg University, Department of Chemistry and Biosciences, A.C. Meyers

Vænge 15, 2450 Copenhagen (Denmark) 
Abstract

17

Crude glycerol is an important by-product of the biodiesel industry, which can be converted into volatile fatty acids (VFA) and/or 1,3-propanediol (1,3-PDO) by fermentation. In this study, a selective conversion of VFA to polyhydroxyalkanoates (PHA) was attained while leaving 1,3-PDO in the supernatant by means of mixed microbial consortia selection strategies. The process showed highly reproducible results in terms of PHA yield, $0.99 \pm 0.07 \mathrm{C}_{\text {mol }} \mathrm{PHA} / \mathrm{C}_{\mathrm{mol}} \mathrm{S}(0.84 \mathrm{~g}$ COD PHA/g COD S), PHA content (76 $\pm 3.1 \mathrm{~g} \mathrm{PHA} / 100 \mathrm{~g}$ TSS $)$ and 1,3-PDO recovery $(99 \pm 2.1 \%)$. The combined process had an ultimate yield from crude glycerol of $0.19 \mathrm{~g} \mathrm{COD} \mathrm{PHA} \mathrm{and} 0.42 \mathrm{~g}$ COD 1,3-PDO per $\mathrm{g}$ of input COD. The novel enrichment strategy applied for selectively transforming fermentation by-products into a high value product (PHA) demonstrates the significance of the enrichment process for targeting specific bio-transformations and could be potentially proved valuable for other biotechnological applications as well.

\section{Keywords}

Polyhydroxyalkanoates; PHA; crude glycerol; mixed microbial consortia; 1,3-propanediol; enrichment 
1,3-PDO: 1,3-propanediol

$\mathrm{C}_{\text {mol }}$ : moles of carbon

COD: Chemical Oxygen Demand

HB: 3-Hydroxybutyrate

HP: 3-Hydroxypropionate

HV: 3-Hydroxyvalerate

MMC: Mixed Microbial Consortia/Cultures

OTU: Operational Taxonomic Unit

PHA: Polyhydroxyalkanoates

$\mathrm{q}_{\mathrm{p}}$ : Specific PHA formation rate $\left(\mathrm{C}_{\mathrm{mol}}\right.$ PHA. $\left.\mathrm{C}_{\mathrm{mol}} \mathrm{X}^{-1} \cdot \mathrm{h}^{-1}\right)$

$-q_{\mathrm{s}}$ : Specific substrate uptake rate $\left(C_{\mathrm{mol}}\right.$ S. $\left.C_{\mathrm{mol}} \mathrm{X}^{-1} \cdot \mathrm{h}^{-1}\right)$

$r_{p}$ : PHA formation rate $\left(C_{m M} P H A / h\right.$ or g PHA. $\left.L^{-1} \cdot h^{-1}\right)$

43

$-r_{s}$ : Substrate uptake rate $\left(C_{m M} S / h\right)$

44

$$
\text { SBR: Sequential Batch Reactor }
$$

45

TSS: Total Suspended Solids

46

VFA: Volatile fatty acids

47

X: Cells excluding polymers (PHA and Glycogen)

48

$\mathrm{Y}_{\mathrm{P} / \mathrm{S}}$ : Yield PHA/substrate $\left(\mathrm{C}_{\text {mol }} \mathrm{PHA} / \mathrm{C}_{\text {mol }} \mathrm{S}\right.$ or g COD PHA /g COD S)

49

$\mathrm{Y}_{\text {gly/s }}$ : Yield Glycogen/substrate $\left(\mathrm{C}_{\mathrm{mol}} \mathrm{Gly} / \mathrm{C}_{\mathrm{mol}} \mathrm{S}\right)$

50

$\mathrm{Y}_{\mathrm{X} / \mathrm{S}}$ : Yield biomass/substrate $\left(\mathrm{C}_{\mathrm{mol}} \mathrm{X} / \mathrm{C}_{\mathrm{mol}} \mathrm{S}\right)$

51

Y x/Polymer: Yield Biomass/PHA+Glycogen $\left(\mathrm{C}_{\text {mol }} \mathrm{X} / \mathrm{C}_{\mathrm{mol}} \mathrm{Gly}+\mathrm{PHA}\right)$

52

$\mu$ : Specific biomass growth rate $\left(\mathrm{h}^{-1}\right)$ 
53

54

55

56

57

58

59

60

61

62

63

64

65

66

67

68

69

\section{Introduction}

Crude glycerol is a by-product of the transesterification of fats and oils in the biodiesel industry, with an average glycerol content of $70 \%$ (Zhu et al., 2013). Its world annual production is in the magnitude of millions of tons, which has stimulated the interest for finding high-value applications such as the production of polyhydroxyalkanoates (PHA) (da Silva et al., 2009). PHA are biopolymers produced in microbial cells under conditions of unbalanced growth (Anderson and Dawes, 1990). Their properties largely resemble some commonly used petroleum derived plastics such as polyethylene and polypropylene, for what PHA have been explored as possible renewable and biodegradable alternative during the last decades (Bugnicourt et al., 2014). Nevertheless, the success of PHA in the market is still limited by their high production costs. In this regard, the use of mixed microbial consortia (MMC), which do not require sterilization and generally present a higher tolerance and adaptability to waste substrates, is being studied as a possible alternative (Kourmentza et al., 2017; Valentino et al., 2016).

Only a few studies have attempted the conversion of glycerol into PHA using MMC (Dobroth et al., 2011; Freches and Lemos, 2017; Moita et al., 2014; Moralejo-Garate et al., 2013), with a common observation of co-accumulation of glycogen, which limits the PHA yield. In order to circumvent that, the substrate can first be fermented to volatile fatty acids (VFA), which can then be converted into PHA at high yields and without glycogen production. The resulting three-step process consists of: 1) Fermentation of the substrate into VFA; 2) Enrichment of PHA accumulating MMC; 3) PHA accumulation (Albuquerque et al., 2007; Serafim et al., 2008). However, glycerol fermentation presents another challenge, which is the production of 1,3-propanediol (1,3-PDO) besides VFA. PHA production from 1,3-PDO has recently been demonstrated in MMC subjected to nitrogen limitation during the famine phase of the enrichment step (Burniol-Figols et al., 2018). Conversion of 1,3 PDO to PHA still needs optimization, as the conversion yields obtained so far were lower than the ones generally obtained from VFA and certain glycogen accumulation also occurred.

Given that 1,3-PDO is a high value product with a similar market price as PHA (1.8 €/kg for 1,3PDO (Gargalo et al., 2016) and 1.5-5 €/kg for PHA (Chanprateep, 2010)), an alternative approach could be to avoid the consumption of 1,3-PDO while converting the VFA into PHA. This would result in an increase in the purity of 1,3-PDO in the supernatant while converting VFA into a high value product. 
The presence of substrates which favor the channeling of carbon towards microbial growth instead of PHA accumulation is a general obstacle, as it limits the PHA content of the cells (Marang et al., 2014; Tamis et al., 2014). In a recent study, the selective consumption of VFA over methanol was achieved in an MMC enriched from aerobic sludge using a strategy based on the selective settling capacity of PHA-containing cells (Korkakaki et al., 2016). By reducing the presence of bacteria utilizing methanol, the maximum PHA storage capacity of the culture increased from 48 to $70 \mathrm{wt} \%$ PHA. Along the same line, a selective consumption of VFA over 1,3-PDO has recently been reported using defined co-cultured strains. In the latter case, the outcome was achieved by testing PHA producing strains for their inability to consume 1,3-PDO (Pan et al., 2016).

In the present study, the selective consumption of VFA over 1,3-PDO in the accumulation phase was attained in MMC by not supplying 1,3-PDO during the enrichment phase. More precisely, the enrichment culture was fed with a synthetic medium supplemented with VFA and crude glycerol (Fig. 1). Different substrate concentrations in the accumulation phase were tested in order to evaluate possible inhibition phenomena. Furthermore, the study assessed the stability of the culture and the reproducibility of the process, which are of vital interest and sometimes put under concern in MMC based open-culture processes.

\section{Materials and methods}

\subsection{Crude glycerol fermentation effluent}

Crude glycerol continuous fermentation was performed with an influent concentration of $10 \mathrm{~g} / \mathrm{L}$ of glycerol (14.7 g/L of crude glycerol) as described elsewhere (Burniol-Figols et al., 2018), based on the results obtained in Varrone et al., (2017). The distribution of metabolites in the effluent utilized during the PHA accumulation experiments was the following (g/L): 1,3-PDO: $4.43 \pm 0.16$, butyrate:1.59 \pm 0.13 , propionate: $0.80 \pm 0.15$, acetate: $0.19 \pm 0.04$, glycerol:<0.01, TSS: $0.89 \pm 0.21$. Measured soluble metabolites accounted for an average of $11.6 \pm 0.4 \mathrm{~g} \mathrm{COD} / \mathrm{L}$, while the total soluble COD was around $14 \mathrm{~g} \mathrm{COD}_{\text {total }} / \mathrm{L}$. Soluble nitrogen in the form of $\mathrm{NH}_{4}{ }^{+}$was $2.56 \pm 1.74 \mathrm{mg} / \mathrm{L}$. The effluent was kept at $4^{\circ} \mathrm{C}$ and at $-20^{\circ} \mathrm{C}$ for short and long term storage, respectively, and was centrifuged (15 min at $4000 \mathrm{~g})$ and filtered $(1 \mu \mathrm{m})$ before being used in the PHA accumulation phase.

\subsection{Enrichment (SBR)}


The enrichment in PHA producers was carried out in a $2.5 \mathrm{~L}$ Minifors reactor (INFORS HT) operating as Sequential Batch Reactor (SBR) with a working volume of $1.7 \mathrm{~L}$. The reactor was operated in cycles of $12 \mathrm{~h}$. At the end of each cycle, half of the volume of the reactor was replaced with fresh medium resulting in a Hydraulic Retention Time (HRT) and Solids Retention Time (SRT) of 1 day. The inoculum (30\% v/v in the first cycle) was a mixture of equal parts of anaerobic sludge from the Lundtofte wastewater treatment plant and aerobic sludge from the Daka Biodiesel wastewater treatment plant (Denmark). Air was supplied at a rate of $1 \mathrm{~L} / \mathrm{min}$ and agitation was set at $500 \mathrm{rpm}$. $\mathrm{pH}$ and temperature were maintained at 8 and $30^{\circ} \mathrm{C}$, respectively. The reactor was emptied and cleaned along with the tubing once a week to avoid excessive biofilm formation.

The medium consisted of BA Medium (Varrone et al., 2015) supplemented with VFA and crude glycerol to a carbon concentration of $90 \mathrm{mM}$ of Carbon $\left(\mathrm{C}_{\mathrm{mM}}\right)\left(45 \mathrm{C}_{\mathrm{mM}}\right.$ at the beginning of the cycle). Half of the carbon corresponded to glycerol $\left(45 \mathrm{C}_{\mathrm{mM}}\right)$, which was added in the form of crude glycerol (1.88 g/L). The crude glycerol source and characteristics can be found elsewhere (Varrone et al., 2015). The other half of the carbon was in the form of VFA (45 $\left.\mathrm{C}_{\mathrm{mm}}\right)$, which were added to the same proportions as in the crude glycerol fermentation effluent: (acetate $2.38 \mathrm{C}_{\mathrm{mm}}$, propionate $12.10 \mathrm{C}_{\mathrm{mm}}$, butyrate $\left.30.52 \mathrm{C}_{\mathrm{mM}}\right) . \mathrm{C}: \mathrm{N}: \mathrm{P}$ molar ratio in the medium was fixed at of $100: 12: 1.5$ with $\mathrm{NH}_{4} \mathrm{Cl}$ and $\mathrm{K}_{2} \mathrm{HPO}_{4}$. Allylthiourea (5mg/L) and Antifoam 204 (Sigma) $(85 \mu \mathrm{L} / \mathrm{L})$ were supplied to inhibit nitrification and foaming, respectively. The resulting organic loading rate of the SBR was $3.7 \mathrm{~g} \mathrm{COD}$ total $\cdot \mathrm{L}^{-1} \cdot \mathrm{day}^{-1}$.

The oxygen saturation $\left(\mathrm{pO}_{2}\right)$ was monitored online and used as an indicator of the duration of the feast phase. This parameter was used, together with the PHA content at the end of the feast phase, to assess the stability of the reactor. Moreover, a full cycle was periodically characterized by offline samples (see analytical methods).

\subsection{PHA accumulation}

Batch tests were performed using the culture from the enrichment at the end of the cycle (12h). $0.85 \mathrm{~L}$ of cell culture were allowed to settle in a volumetric cylinder for 30 minutes, followed by removal of $0.65 \mathrm{~L}$ of supernatant. At time 0 of the batch experiment, the remaining $0.2 \mathrm{~L}$ of settled cells were added to $1.5 \mathrm{~L}$ of medium consisting of clarified crude glycerol fermentation effluent diluted with distilled water to reach different VFA concentrations $\left(45 \mathrm{C}_{\mathrm{mM}}, 60 \mathrm{C}_{\mathrm{mM}}, 75 \mathrm{C}_{\mathrm{mm}}\right.$ and $\left.90 \mathrm{C}_{\mathrm{mm}}\right)$ at the beginning of the batch, corresponding to 5.6, 7, 9.5 and $12 \mathrm{~g} \mathrm{COD}_{\text {total }} / \mathrm{L}$. The correspondent cycle of the SBR for each batch is indicated in Table 1. Allylthiourea and antifoam were supplied to the concentrations described above for the SBR. Aeration, agitation and $\mathrm{pH}$ control were also carried out 
like described above for the SBR. Likewise, phosphorous was added to a final C:P ratio of 100:1.5. No nitrogen was supplemented in order to provide nitrogen limiting conditions.

After the initial assays at increasing VFA concentrations, the PHA accumulation batch at $90 \mathrm{C}_{\mathrm{mm}}$ was repeated 11 times to assess the reproducibility of the results during a period of 2 months (Table 1). The batches were stopped after butyrate depletion, indicated by a raise in the oxygen saturation. The reproducibility of the tests was assessed by the PHA content of the cells at the end of the batch. Moreover, in five of the batches (indicated in bold in Table 1), the rates and yields of the process where characterized by frequent offline sampling. Linear correlations of variables were assessed by means of the Pearson correlation coefficient and 2-tailed test of significance using the software OriginPro v 9.0.0.

\subsection{Analytical methods}

Offline samples of the reactors were characterized as follows. Total suspended solids (TSS) were measured in fresh samples using Whatman filters GF/F and according to standard protocols (APHA et al., 2005). Samples were thereafter centrifuged (at $4000 \mathrm{~g}$ for $10 \mathrm{~min}$ ) and the pellets were washed with PBS solution (phosphate-buffered saline) and freeze dried. PHA and glycogen in lyophilized cell pellets were measured in duplicate according to the protocols described in Burniol-Figols et al., (2018), and expressed as a weight percentage of the TSS. The PHA and glycogen content was subtracted from the TSS to obtain the concentration of active biomass (cells excl. polymers or X). The supernatant was filtered $(0.45 \mu \mathrm{m})$ and kept at $-20^{\circ} \mathrm{C}$ prior to analysis of soluble nitrogen $\left(\mathrm{N}^{\left.-\mathrm{NH}_{3}\right)}\right.$ (Hach-Lange kits LCK 305/303), COD (Hach-Lange kits LCK 914/514), as well as VFA and alcohols concentrations. VFA (acetate, propionate, iso and $n$-butyrate, lactate, iso and $n$-valerate and hexanoate) and alcohols (1,3-PDO, butanol and glycerol) in the supernatant were analyzed by HPLC in a Shimadzu HPLC system equipped with an RI detector and an Aminex HPX-87H column (BioRad). Yields and rates were calculated as previously reported (Burniol-Figols et al., 2018). Parameters reported in terms of $\mathrm{C}_{\text {mol }}$ were based on the compounds measured by HPLC, while parameters reported in terms of $\mathrm{COD}_{\text {total }}$ were based on the measurements of the soluble COD in the supernatants. The dilution effect of acid and base addition for the $\mathrm{pH}$ control, as well as the effect of the sampling, were taken into account for all calculations.

PHA were extracted in chloroform and analyzed by Nuclear Magnetic Resonance spectroscopy $\left({ }^{1} \mathrm{H}-\mathrm{NMR}\right.$ and $\left.{ }^{13} \mathrm{C}-\mathrm{NMR}\right)$ as described in Burniol-Figols et al., (2018). The molar mass of the polymer was determined by Size-Exclusion Liquid Chromatography (SEC) in a Shimadzu HPLC system using 


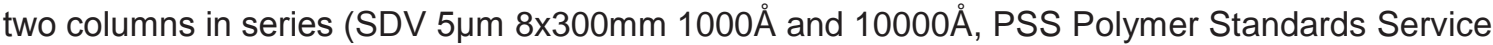
$\mathrm{GmbH})$. The oven temperature was set at $31^{\circ} \mathrm{C}$. Chloroform was used as eluent at a flow rate of $1 \mathrm{~mL} / \mathrm{min}$. The system was calibrated with low polydispersity polystyrene standards (Polymer Standards Service $\mathrm{GmbH})$.

Microbial analyses were performed in samples corresponding to time 0 of the SBR cycles indicated in Table 1. Sampling, DNA extraction, 16S rRNA gene amplicon sequencing and data processing were performed as described in Burniol-Figols et al., (2018). Sequencing reads have been deposited to the Sequence read archive of NCBI under the BioProject ID: PRJNA398362.

\section{Results and discussion}

\subsection{Enrichment of PHA-accumulating MMC in absence of 1,3-PDO}

The present study was based on the hypothesis that an MMC subjected to a feast and famine regime using medium supplied with VFA, but not 1,3-PDO, would be enriched in bacteria adapted to accumulate PHA predominantly from VFA. Consequently, a culture selected in this manner would not consume 1,3-PDO when supplied with real fermentation effluent containing both substrates in the following PHA accumulation phase (Fig. 1). Therefore, the PHA enrichment was performed in an SBR fed with a synthetic VFA medium. Nevertheless, in order to avoid any inhibition phenomena when the culture faced the real waste effluent in the PHA accumulation, the VFA synthetic medium was supplemented with crude (non-fermented) glycerol.

During the first cycles, VFA were consumed faster than glycerol (Fig. 2 A). Nonetheless, from cycle 50 onwards, the depletion of either substrate was not distinguishable any more from the $\mathrm{pO}_{2}$ profile, as exemplified by a typical cycle of the stabilized reactor in Fig. 3 A and B. Complete substrate consumption occurred within $65 \mathrm{~min}$, representing a feast/famine ratio of 0.1 (Fig. $3 \mathrm{~B}$ ). Substrate consumption coincided with a PHA production up to $37.3 \mathrm{wt} \%$, detecting an increment in both HB (3hydroxybutyrate) and HV (3-hydroxyvalerate) monomers (Fig. 3 C and D). Glycogen was also formed during the feast phase, probably from glycerol, given the tendency of the latter to lead coaccumulation of glycogen and PHA (Moralejo-Gárate et al., 2011). The PHA yield was $0.68 \mathrm{C}_{\mathrm{mol}}$ $\mathrm{PHA} / \mathrm{C}_{\text {mol }}$ substrate and the glycogen yield represented $0.12 \mathrm{C}_{\text {mol }}$ glycogen $/ \mathrm{C}_{\text {mol }}$ substrate (Table 2 ). During the famine phase, these polymers were transformed into biomass (Fig. $3 \mathrm{C}$ ) at a yield of 0.62 $\mathrm{C}_{\text {mol }}$ biomass $/ \mathrm{C}_{\text {mol }}$ polymers using the nitrogen present in the medium (Table 2 ). 
The SBR proved to be very stable both in terms of duration of the feast phase and the PHA content of the cells at the end of the feast phase (Fig. 2 A and B). Table 2 displays the yields and rates obtained in two different cycles separated for more than 3 months, which presented practically the same values.

\subsection{Microbial community analysis}

The culture in the SBR was dominated by OTUs (Operational Taxonomical Units) classified within the genera Amaricoccus (class Alphaproteobacteria) and Thauera (class Betaproteobacteria), which together accounted for 56.3-72.4\% of the sequences at different cycles of the SBR (Fig. 4). The other identified OTUs rarely presented abundances higher than $5 \%$, suggesting a highly diverse flanking population.

Both dominant genera, Thauera and Amaricoccus have largely been reported to be prevalent genera in PHA enrichment reactors operated under feast/famine aerobic regime, especially in the case of Thauera (Morgan-Sagastume, 2016). Moreover, both genera have been directly correlated with PHA accumulation by means of Nile Blue staining (Lemos et al., 2008).

In regard to substrate utilization, different substrate preferences have been reported for these genera. Members of the Amaricoccus genus were described to become dominant over Thauera when the substrate of the SBR changed from acetate to propionate (Lemos et al., 2008). However, Yang et al., (2013) identified Thauera to be the main genus in a propionate-fed SBR. On the other hand, bacteria from the genus Thauera were described to primarily use butyrate as a carbon source when submitted to a mixture of VFA (Albuquerque et al., 2013). To our knowledge, neither of the two genera has been previously described in glycerol-fed systems.

Fluctuations of the relative abundance of the main genera, as well of the sum of the two, were observed in samples taken at different points, despite a steady behavior of the SBR (Fig. 4). This is very well exemplified in the two SBR cycles presented in Table 2 (cycle 298 and 76). The yields and rates of these cycles were very similar despite substantial variations in the microbial population identified at the beginning of the cycles (Fig. 4). The percentage of OTUs classified within the genus Thauera was much higher in cycle 298 (29.1 vs. 18.9), and concurrent with a clear drop in the genus Amaricoccus (37.9 vs 27.2 ). Nonetheless, the sum of the two main genera was virtually the same. Stable operation of SBRs with variations in the relative composition of the microbial population has been previously reported (Bengtsson, 2009; Serafim et al., 2006; Valentino et al., 2014). Albuquerque et al., (2013) demonstrated that microbial strains with PHA production capacity can compete for the 
same substrate. Thus, small variations in the microbial composition do not necessary imply a change in the overall performance. From the results obtained here, a relative abundance of the two main genera over $50 \%$ seemed to be a common denominator for a stable operation of the SBR.

\subsection{PHA accumulation with 1,3-PDO recovery}

Using the enriched inoculum from the SBR, a set of experiments of PHA accumulation with crude glycerol fermentation effluent was performed at different initial VFA concentrations: $45 \mathrm{C}_{\mathrm{mM}}, 60 \mathrm{C}_{\mathrm{mM}}$, $75 \mathrm{C}_{\mathrm{mm}}$ and $90 \mathrm{C}_{\mathrm{mm}}$, with the last corresponding to undiluted effluent (Fig. 5 and Table 3).

For all the concentrations tested, butyrate was used up before acetate and propionate, even though the initial concentrations of these VFA were lower (Fig. 5 C). Acetate and propionate concentrations decreased right from the beginning, but their consumption rates increased once butyrate was depleted (Table 3, Fig. 5 C). This fact was translated into two different phases of PHA accumulation, which could be clearly distinguished by the $\mathrm{pO}_{2}$ saturation profile (Fig. $5 \mathrm{~A}$ ).

During the first phase, coinciding with butyrate consumption, a steep increase in the PHA concentration and polymer content was observed. HB was the main monomer produced, but a notable production of HV also occurred (Fig. $5 \mathrm{D}$ and E). A small increment in 3-hydroxypropionate (HP) was detected as well, but never reaching values over $1 \mathrm{wt} \%$. PHA yields during this phase (hereafter referred to as butyrate phase) were higher than $0.9 \mathrm{C}_{\mathrm{mol}} \mathrm{PHA} / \mathrm{C}_{\mathrm{mol}} \mathrm{S}$ in all experiments (Table 3). Around $80 \%$ of the substrate was consumed during this phase.

During the second phase, when only acetate and propionate were available, only a slight increase in PHA concentration was observed (Fig. 5 D). The PHA yields were much lower than during the butyrate phase and a considerable increase in the carbon derived to growth was observed for all batches (Table 3). As a result, the overall PHA yields for the entire batch presented always a lower value than during the butyrate phase (Table 3 ).

Similar observations regarding the preference of butyrate over acetate and propionate have been reported previously in cultures dominated by different microbial genera (Albuquerque et al., 2013; Jiang et al., 2012; Marang et al., 2013). As a matter of fact, this phenomenon has been observed even in cultures that were not exposed to butyrate during the enrichment (Dionisi et al., 2005). In a study with only butyrate and acetate as a substrates (Marang et al., 2013), butyrate depletion before acetate led to the same phases observed here, where specific substrate carbon consumption rates (in $\mathrm{C}_{\mathrm{mol}} \mathrm{S} . \mathrm{C}_{\mathrm{mol}} \mathrm{X}^{-1} \cdot \mathrm{h}^{-1}$ ) decreased during the second phase. Nonetheless, the specific substrate consumption rate in terms of mol S. $\mathrm{C}_{\mathrm{mol}} \mathrm{X}^{-1} \cdot \mathrm{h}^{-1}$ remained constant troughout the two phases. This fact 
indicated that the substrate uptake and activation was the rate-limiting process and that butyrate and acetate shared the same transporter, but it had preference for butyrate. The same phenomenon was observed in the present study: a decrease in the specific substrate carbon uptake rate (in $\mathrm{C}_{\mathrm{mol}} \mathrm{S} . \mathrm{C}_{\mathrm{mol}}$ $\mathrm{X}^{-1} \cdot \mathrm{h}^{-1}$ ) was observed after butyrate exhaustion, but the specific substrate rate in terms of substrate mols was mantained (except for the batch at $75 \mathrm{C}_{\mathrm{mm}}$, Table 3). Nevertheless, this condition was only met when propionate was considered, which, following the same reasoning as in Marang et al., (2013), would indicate that propionate is also uptaken through the same regulation system.

The lower PHA yields obtained during the second phase could be related to various factors. Higher PHA yields have been associated to butyrate compared to acetate, and attributted to the lower ATP needs of the transformation to PHB, thus a reducing carbon flux to the TCA cycle (Marang et al., 2013). Propionate has also usually been reported to present lower PHA yields and higher growth yields compared to acetate (Dias et al., 2008; Jiang et al., 2011). In this case, a lower PHA yield would not be justified by higher energy requirements, but partially because of the loss of carbon during HV production (Pardelha et al., 2012), which justifies in the following argument. HV arises from the condensation of acetyl-CoA and propionyl-CoA. When acetyl-coA is available from the transformation of other substrates (such as butyrate), all the propionate can be converted to propionyl-CoA and incorporated into HV. Nonetheless, when acetyl-coA is not available, propionyl$\operatorname{coA}$ has to be decarboxylated to acetyl-coA, thus lowering the maximum theoretical PHA yield to 0.67 $\mathrm{C}_{\text {mol }} \mathrm{PHA} / \mathrm{C}_{\mathrm{mol}} \mathrm{S}$. In the present case, propionyl-coA from propionate could be combined with acetylCoA originated from the other VFA during the butyrate phase, and as a matter of fact, over $70 \%$ of propionate consumed was recovered as HV (mol basis). During the second phase, the little acetate present in the medium could not provide enough acetyl-coA molecules, so decarboxylation of propionyl-coA to acetyl-coA was needed. During this phase, under $30 \%$ of the propionate consumed was recovered as HV (mol basis). This behaviour, which might partially explain the lower yields, is very well illustrated in Fig. 5, where despite the propionate consumption rate increased during the second phase of the batch (Fig. 5 C), the HV monomers continued increasing at the same rate as earlier (Fig. 5 D).

Overall, the lower PHA yields combined with lower substrate uptake rates (in $\mathrm{C}_{\text {mol }}$ ) led to a reduction of the PHA production rate during the second phase. Moreover, a reduction of the apparent PHA production rate could have occurred due to a simultaneous degradation of the PHB produced during the butyrate phase. Nonetheless, the last hypothesis could not be confirmed from the data obtained here. 
Measurements of the COD in the supernatant always resulted in higher values than calculated from the sum of identified compounds in the HPLC. Partial consumption of this undefined COD, probably crude glycerol impurities, was observed (Fig. 5 B). Whether these compounds contributed to the observed PHA production could not be ruled out with the analyses performed here. Thus, the PHA yields calculated from the overall COD consumed are also reported in Table 3. It is noteworthy to mention that, despite these yields were lower, they presented the same tendencies as the ones calculated on VFA basis.

Another very important general observation in all experiments was the negligible consumption of 1,3-PDO, which was recovered to a minimum of 95\% (Fig. 5 B and Table 3). This value was much higher than the recovery obtained when a similar strategy was tested by selecting defined PHA strains for their incapacity to consume 1,3-PDO (Pan et al., 2016). That strategy resulted in a 1,3PDO recovery of $80 \%$ and a PHA content of around $20 \mathrm{wt} \%$ after $28 \mathrm{~h}$ of incubation. The higher selectivity for VFA obtained in the present study using MMC might be due to the high responsiveness to substrate addition developed by cultures submitted to feast/famine regimes.

The presence of VFA as by-products is common in biological processes such as lactic acid, ethanol or butanol fermentations. The strategy presented here could be tested in other fermentation effluents in order to increase the purity of the desired product while producing PHA as an additional high value product.

\subsection{Effect of increasing substrate concentration on the PHA accumulation}

The PHA accumulation experiments performed at different VFA concentrations also exhibited some differences in the followed parameters, which are summarized in Fig. 6. Given the different phases observed (described in the previous section) the results are presented both for the overall VFA consumption and the butyrate consumption phase. The polymer percentage inside the cells incremented linearly with the initial substrate concentration until $75 \mathrm{C}_{\mathrm{mM}}$, where 70 wt\% PHA was reached (Fig. 6 A). No further increase was observed at $90 \mathrm{C}_{\mathrm{mm}}$ initial concentration. Nevertheless, a higher PHA concentration was obtained at $90 \mathrm{C}_{\mathrm{mM}}$, derived from the higher TSS obtained at this concentration. As a matter of fact, there was a linear increase in the maximum PHA concentration obtained at the end of the feast phase (Fig. 6 B), reaching up to $1.79 \mathrm{~g} / \mathrm{L}$ of PHA at the highest concentration. 
suggest a decreasing trend of the PHA yield (considering the data points at $60 \mathrm{C}_{\mathrm{mm}}$ as outliers).

Alternatively, no trends would be perceived if the batch at $45 \mathrm{C}_{\mathrm{mM}}$ was considered an outlier. Looking at the specific substrate uptake rates $\left(q_{s}\right)$ and the specific product formation rates $\left(q_{p}\right)$ (Fig. 6 D and E), no important differences could be observed. Both parameters seemed to be independent of the substrate concentration. Thus, substrate inhibition could not be concluded from the data. Noteworthy to mention, this lack of inhibition occurred despite increasing concentrations of 1,3-PDO.

Overall, increasing the VFA initial concentration up to $90 \mathrm{C}_{\mathrm{mM}}$ did not have an apparent effect on the main outcome of the PHA accumulation, the specific substrate concentration rate $\left(q_{p}\right)$. At this concentration, a higher PHA concentration was obtained, which would benefit the downstream costs of the process. Given the different phases observed, it would be reasonable to stop the process after butyrate depletion in order to maintain a high productivity. At this point, the PHA would be produced at a yield of $0.91 \mathrm{C}_{\text {mol }} \mathrm{PHA} / \mathrm{C}_{\text {mol }} \mathrm{S}$ with an specific rate of $0.87 \mathrm{C}_{\text {mol }} \cdot \mathrm{C}_{\mathrm{mol}} \mathrm{X}^{-1} \cdot \mathrm{h}^{-1}$ (Table 3). The 1,3-PDO would be recovered at $97 \%$ and would represent $80 \%$ of the COD of the supernatant. This figure would increase up to $85 \%$ if the rest of the VFA were allowed to be depleted. Nevertheless, the yield would decrease to an overall yield of $0.81 \mathrm{C}_{\mathrm{mol}} \mathrm{PHA} / \mathrm{C}_{\mathrm{mol}} \mathrm{S}$ and the productivity would drop to $0.5 \mathrm{C}_{\mathrm{mol}}$ PHA.C $\mathrm{mol}_{\mathrm{mol}} \mathrm{X}^{-1} \cdot \mathrm{h}^{-1}$ (Table 3). Consequently, different strategies could be formulated based on a general economic evaluation, taking into account the cost of the further purification of 1,3-PDO depending on the purity of the effluent and the repercussion of the decrease of productivity.

\subsection{Reproducibility of the PHA accumulation}

The PHA batch accumulation at the highest initial VFA concentration $\left(90 \mathrm{C}_{\mathrm{mm}}\right)$ was repeated 11 times over a period of 2 months to study the stability of the culture (Table 1). The batches were stopped after butyrate depletion, indicated by as sudden increase in the oxygen saturation (Fig. $5 \mathrm{~A}$ ). The average PHA content obtained at the end of the 11 batches was $76 \pm 3.1 \mathrm{wt} \%$ (Table 4) implying a relative error of just $4 \%$. The HB: HV ratio was also reproducible, with the average value being $84: 16( \pm 2.0: 1.8)$. In the same line, 1,3-PDO was always completely recovered from the fermentation broth, with an average recovery of $99 \pm 2.1 \%$. reproducible values were obtained in terms of PHA yield and maximum PHA concentration, with average values of $0.99 \pm 0.07 \mathrm{C}_{\mathrm{mol}} \mathrm{PHA} / \mathrm{C}_{\mathrm{mol}} \mathrm{S}(0.84 \mathrm{~g} \mathrm{COD} \mathrm{PHA} / \mathrm{g}$ COD S) and $1.48 \pm 0.14 \mathrm{~g} \mathrm{PHA} / \mathrm{L}$, respectively. 
A slightly higher degree of variability was observed in terms of rates (Table 5). The substrate uptake rate $\left(r_{s}\right)$ and PHA production rate $\left(r_{p}\right)$ presented relative standard deviations of $15 \%$ and $12 \%$, respectively. These standard deviations were mainly caused by a decline of the rates in batches 9 and 10 , in which the duration of the batches (defined by the depletion of butyrate and thus by the rate of butyrate consumption $\left.\left(\mathrm{r}_{\mathrm{s} \text { but }}\right)\right)$ increased from $3 \mathrm{~h}$ to $5 \mathrm{~h}$ and $4 \mathrm{~h}$ respectively. In those batches, the $r_{\mathrm{s} \text { but }}$ presented values of around $13 \mathrm{C}_{\mathrm{mm}} / \mathrm{h}$, much lower than obtained in the initial test $\left(21.6 \mathrm{C}_{\mathrm{mm}} / \mathrm{h}\right)$. Noteworthy, the decrease in $r_{s \text { but }}$ was not accompanied with a decrease in the specific substrate consumption for butyrate $\left(\mathrm{q}_{\mathrm{s} \text { but }}\right)$, which, on the contrary, increased considerably in all the repeats compared to the initial PHA accumulation test. Nonetheless, an important decrease of the initial biomass concentration (TSS ${ }_{\text {ini }}$ ) was observed (from $0.77 \mathrm{~g} / \mathrm{L}$ in the initial test to an average of $0.46 \mathrm{~g} / \mathrm{L}$ in the repetitions). A linear correlation was observed between the initial TSS concentration and $r_{s}, r_{s}$ but and $r_{p}$ (significance level $\left.(\alpha)<0.05\right)$. No significant correlation was obtained between the TSS and specific substrate consumption rates $\left(\mathrm{q}_{\mathrm{s}}\right.$ and $\left.\mathrm{q}_{\mathrm{s} \text { but }}\right)$.

Remarkably, the lower initial TSS was not caused by a decreased biomass at the end of the SBR cycle, which even slightly increased in later cycles of the SBR (Table 5), but was due to a loss of biomass in the settling step between the SBR and the PHA accumulation. The absolute TSS lost in the clarified fraction was quantified to be $8 \%$ of the inoculum in the initial test (B90), while around $50 \%$ in the batches 9, 10 and 12 (Table 5).

Correlations were also investigated between the observed parameters and the composition of the microbial population used as inoculum (Fig. 4). No significant correlations $(\alpha<1)$ were obtained between any of the rates $\left(r_{s}, r_{p}, r_{s}\right.$ but, $q_{s}$ and $\left.q_{p}\right)$ and the relative abundance of Thauera, Amaricoccus or the sum of the two. However, in terms of concentration of those genera $(\mathrm{g} / \mathrm{L}$ instead of relative abundance), a significant correlation was obtained between $r_{s \text { but }}$ and $r_{p}$ with the sum of Amaricoccus and Thauera $(\alpha<0.05)$. Thus, giving further evidence that the performance of the systems seemed to be governed by the initial cells concentration (TSS), and consequently of the main genera, rather than the relative composition of the culture. It is important to notice though, that these correlations were not established with the biomass composition present at the beginning of the PHA accumulation but with the biomass used as inoculum, which was the main interest of the study and the most likely source of variations. Consequently, possible changes in relative percentages occurring during the sedimentation step, which could have hampered the correlations, cannot be excluded. filamentous bulking) (Martins et al., 2004; Morgan-Sagastume et al., 2015). Reported filamentous 
genera (Nielsen et al., 2009) were found in very minor quantities in the analyzed samples, generally below $0.2 \%$. Only OTUs classified in the genera Acidovorax (0.3-1.1\%), Acinetobacter (0.05-3.4\%) and Dyadobacter (1.2-9.6\%), of which some members are described to have filamentous growth (Chelius and Triplett, 2000; Nielsen et al., 2009), reached higher abundances. Nevertheless, no correlations were observed between the TSS and the relative abundance of filamentous genera, neither individually nor as a sum. On the other hand, bulking effect can also be caused by the overproduction of exopolysaccharides, typically attributed to the genus Zooglea (Janarthanan et al., 2016; Jenkins, 1992). Members of the genus Thauera, closely related to Zooglea, have also been reported to be related to such episodes in activated sludge (Allen et al., 2004; Lajoie et al., 2000). In the present study, the relative abundance of OTUs classified as Thauera increased in all PHA accumulation repeats compared to the initial test (Fig. 4). Thus, exopolysaccharides production, as well as its potential causes, such as nutrient availability and toxicity factors (Sheng et al., 2010), should be further investigated as possible elements causing differences in the settlement behavior.

Interestingly, the TSS at the beginning of the batch had a linear correlation with the initial PHA content of the cells (Table 5). High PHA contents are known to favor cell settlement, due to increased density (Korkakaki et al., 2016). Nonetheless, differences observed here (from 1.6-4.4 wt\%) could not justify important differences in the cell density. Alternatively, the PHA content at the end of the famine phase could be read as an indication of the physiological state of the cells, affecting their settling behavior. Similar observations were reported in the study of Valentino et al., (2015).

All in all, the causes of insufficient settling should be further investigated and avoided in order to consolidate a robust process and to maximize the transfer of biomass from the enrichment to the PHA accumulation. Alternatively, the implementation of flocculation agents or a centrifugation step could be considered.

\subsection{Analysis of the polymer}

413 In order to rule out the presence of any other PHA unit besides the ones measured by GC 414 chromatography (HB, HV, HP), NMR analysis of the polymer was performed. This analysis was 415 especially important given the observed partial consumption of undefined COD during the batches, 416 which could have given unexpected PHA monomers. However, NMR results of the chloroform 417 extracted PHA at the end of the butyrate phase confirmed the presence of only HB and HV 418 monomers. Moreover, HB-HV bonds could be identified in the ${ }^{13} \mathrm{C}-\mathrm{NMR}$, revealing that the HB and HV 419 units were in the form of a copolymer P(HB-co-HV) (Fig. A.1 and A.2 Supplementary materials). 
SEC analysis displayed a unimodal distribution, corroborating that a copolymer was formed from

HB and HV monomers during PHA accumulation (Fig. A.3 Supplementary materials). The weightaverage molar mass $\left(\overline{M_{w}}\right)$ was $529 \mathrm{~kg} / \mathrm{mol}$ and the polydispersity index 2.37 , which are values in the range of those previously reported for $\mathrm{MMC}$, and a priori acceptable for thermoplastic applications (Laycock et al., 2014).

\subsection{Overview of the developed process}

The average PHA yield $\left(0.99 \mathrm{C}_{\text {mol }} \mathrm{PHA} / \mathrm{C}_{\mathrm{mol}} \mathrm{S} ; 0.84 \mathrm{~g}\right.$ COD/g COD), PHA content $(76 \mathrm{wt} \%)$ and rate $\left(1.13 \mathrm{C}_{\text {mol }}\right.$ PHA. $\mathrm{C}_{\text {mol }} \mathrm{X}^{-1} \cdot \mathrm{h}^{-1}$ or $\left.0.41 \mathrm{~g} \mathrm{PHA} \cdot \mathrm{L}^{-1} \cdot \mathrm{h}^{-1}\right)$ obtained in the present study during the PHA accumulation were in the very high range of results previously reported in the literature (Valentino et al., 2016). The highest yield obtained from crude glycerol in $M M C$ is of $0.51 \mathrm{C}_{\mathrm{mol}} \mathrm{PHB} / \mathrm{C}_{\mathrm{mol}}$ glycerol (Freches and Lemos, 2017), which led to $59 \mathrm{wt} \%$ PHA. Considering as well the stoichiometry of the fermentation, $1 \mathrm{C}_{\mathrm{mol}}$ of glycerol would produce $0.50 \mathrm{C}_{\mathrm{mol}}$ of $1,3-\mathrm{PDO}$ and $0.23 \mathrm{C}_{\mathrm{mol}} \mathrm{PHA}$, resulting in an overall carbon recovery of $0.73 \mathrm{C}_{\mathrm{mol}} \mathrm{C}_{\mathrm{mol}}$. This value would be higher than producing PHA directly from glycerol, which has a theoretical maximum of $0.67 \mathrm{C}_{\mathrm{mol}} \mathrm{PHB} / \mathrm{C}_{\mathrm{mol}}$ glycerol due to the $\mathrm{CO}_{2}$ release occurring during the production of acetyl-coA as intermediate (Moralejo-Gárate et al., 2011).

In terms of total COD, and considering the total COD input of the three steps of the process (consumed or not), the overall COD recovered in the products would be $0.61 \mathrm{~g} \mathrm{COD} / \mathrm{g} \mathrm{COD}_{\text {in }}(0.19 \mathrm{~g}$ COD PHA/g COD in and $0.42 \mathrm{~g} \mathrm{COD} 1,3-\mathrm{PDO} / \mathrm{g} \mathrm{COD}_{\text {in }}$ ) (Fig.7 B). Remarkably, this value would not increase any further by leaving the substrate to be totally consumed. Moreover, it is important to note that the COD provided in the enrichment represented only $12 \%$ of the total input, due to the low organic loading rate of this reactor. The total COD recovered as products was much higher than the maximum overall yield reported from PHA production directly from crude glycerol $(0.32 \mathrm{~g} \mathrm{COD} \mathrm{PHA} / \mathrm{g}$ $C O D_{\text {in }}$ in Moita et al., 2014). It was also higher than preliminary results obtained through crude glycerol fermentation and conversion of both VFA and 1,3-PDO to PHA (0.31 g COD PHA/g COD total in Burniol-Figols et al., 2018).

Besides the advantages in terms of COD recovery, the process may also present a value in terms of the type of PHA produced. No other monomers besides HB have been described in PHA produced from direct transformation of glycerol (Zhu et al., 2013). In contrast, the PHA produced here from fermented crude glycerol included both HB and HV units. This could represent a further advantage of the suggested three step process, as $\mathrm{P}(\mathrm{HB}-\mathrm{co}-\mathrm{HV})$ copolymers are described to have better thermoplastics properties than PHB (Laycock et al., 2014). 
A future development of the process should include the investigation of higher substrate

452 concentrations, observing possible inhibition phenomena from 1,3-PDO or other inhibitory components in crude glycerol. Moreover, avoiding the use of synthetic substrates in the SBR could be evaluated. Despite the input being minor compared to the total COD (Fig. 7), its substitution would probably benefit the economics of the process. The use of other fermentation effluents containing only VFA or crude glycerol alone could be tested.

\section{Conclusions}

Using fermented crude glycerol and mixed microbial consortia (MMC), the present study assessed the possibility to selectively convert volatile fatty acids (VFA) into polyhydroxyalkanoates (PHA) while leaving 1,3-propanediol (1,3-PDO) in the supernatant. The following conclusions could be extracted:

- Selective consumption of VFA over 1,3-PDO was attained by using microbial biomass enriched in the absence of 1,3-PDO.

- The PHA accumulation led, on average, to $76 \pm 3.1 \mathrm{wt} \% \mathrm{PHA}$ in the form of a copolymer of $\mathrm{P}(\mathrm{HB}-\mathrm{co}-\mathrm{HV})$, with a complete recovery of $1,3-\mathrm{PDO}(99 \pm 2.1 \%)$.

- The SBR reactor presented a steady behavior despite changes in the relative percentage of the main genera of the MMC: Thauera and Amaricoccus.

- Highly reproducible values were obtained in terms of PHA yield and maximum PHA concentration, with average values of $0.99 \pm 0.07 \mathrm{C}_{\mathrm{mol}} \mathrm{PHA} / \mathrm{C}_{\mathrm{mol}} \mathrm{S}(0.84 \mathrm{~g} \mathrm{COD} \mathrm{PHA} / \mathrm{g}$ COD S) and $1.48 \pm 0.14 \mathrm{~g} \mathrm{PHA} / \mathrm{L}$, respectively.

- Small variations in the substrate uptake rates and PHA formation rates during the PHA accumulation were attributed to variations in the biomass settling behavior prior to the PHA accumulation.

- $\quad$ The MMC presented preference for butyrate over acetate and propionate.

- The microbial culture was not inhibited when exposed to up to $90 \mathrm{C}_{\mathrm{mM}}$ of VFA and $150 \mathrm{C}_{\mathrm{mm}}$ of 1,3-PDO, and presented a high PHA production rate of $0.41 \mathrm{~g} \mathrm{PHA} \cdot \mathrm{L}^{-1} \cdot \mathrm{h}^{-1}$.

- Taking into account the three steps of the process (crude glycerol fermentation, enrichment and PHA accumulation), the overall COD recovered as products was $0.61 \mathrm{~g} \mathrm{COD} / \mathrm{g} \mathrm{COD}_{\text {in }}$, where $0.19 \mathrm{~g}$ were in the form of PHA and $0.42 \mathrm{~g}$ in the form of 1,3-PDO. 
Appendix A: Supplementary figures of the polymer analysis

\section{Acknowledgements}

This work was supported by the European Commission (FP7 Grant Agreement no 613667; acronym: GRAIL). Contributions from Tone Haugen and Tonje MB Heggeset in performing the 16S rRNA gene amplicon sequencing are highly appreciated.

\section{References}

Albuquerque, M.G.E., Carvalho, G., Kragelund, C., Silva, A.F., Barreto Crespo, M.T., Reis, M. a M., Nielsen, P.H., 2013. Link between microbial composition and carbon substrate-uptake preferences in a PHA-storing community. ISME J. 7, 1-12. doi:10.1038/ismej.2012.74

Albuquerque, M.G.E., Eiroa, M., Torres, C., Nunes, B.R., Reis, M.A.M., 2007. Strategies for the development of a side stream process for polyhydroxyalkanoate (PHA) production from sugar cane molasses. J. Biotechnol. 130, 411-421. doi:10.1016/j.jbiotec.2007.05.011

Allen, M.S., Welch, K.T., Prebyl, B.S., Baker, D.C., Meyers, A.J., Sayler, G.S., 2004. Analysis and glycosyl composition of the exopolysaccharide isolated from the floc-forming wastewater bacterium Thauera sp. MZ1T. Environ. Microbiol. 6, 780-790. doi:10.1111/j.14622920.2004.00615.x

Anderson, A.J., Dawes, E.A., 1990. Occurrence, metabolism, metabolic role, and industrial uses of bacterial polyhydroxyalkanoates. Microbiol. Rev. 54, 450-472. doi:0146-0749/90/040450$23 \$ 02.00 / 0$

APHA, AWWA, WEF, 2005. Standard Methods for the Examination of Water \& Wastewater, 21st editi. ed.

Bengtsson, S., 2009. The utilization of glycogen accumulating organisms for mixed culture production of polyhydroxyalkanoates. Biotechnol. Bioeng. 104, 698-708. doi:10.1002/bit.22444

Bugnicourt, E., Cinelli, P., Lazzeri, A., Alvarez, V., 2014. Polyhydroxyalkanoate (PHA): Review of synthesis, characteristics, processing and potential applications in packaging. Express Polym. Lett. 8, 791-808. doi:10.3144/expresspolymlett.2014.82

Burniol-Figols, A., Varrone, C., Egede, A.D., Le, S.B., Skiadas, I. V., Gavala, H.N., 2018. Polyhydroxyalkanoates (PHA) production from fermented crude glycerol: Study on the conversion of 1,3-propanediol to PHA in mixed microbial consortia. Water Res. 128, 255-266. 
Chanprateep, S., 2010. Current trends in biodegradable polyhydroxyalkanoates. J. Biosci. Bioeng. 110, 621-632. doi:10.1016/j.jbiosc.2010.07.014

Chelius, M.K., Triplett, E.W., 2000. Dyadobacter fermentans gen . nov ., sp . nov ., a novel Gramnegative bacterium isolated from surface-sterilized Zea mays stems. Int. J. Syst. Evol. Microbiol. 50, 751-758. doi:10.1099/00207713-50-2-751

da Silva, G.P., Mack, M., Contiero, J., 2009. Glycerol: A promising and abundant carbon source for industrial microbiology. Biotechnol. Adv. 27, 30-39. doi:10.1016/j.biotechadv.2008.07.006

Dias, J.M.L., Oehmen, A., Serafim, L.S., Lemos, P.C., Reis, M.A.M., Oliveira, R., 2008. Metabolic modelling of polyhydroxyalkanoate copolymers production by mixed microbial cultures. BMC Syst. Biol. 2, 59. doi:10.1186/1752-0509-2-59

Dionisi, D., Carucci, G., Petrangeli Papini, M., Riccardi, C., Majone, M., Carrasco, F., 2005. Olive oil mill effluents as a feedstock for production of biodegradable polymers. Water Res. 39, 20762084. doi:10.1016/j.watres.2005.03.011

Dobroth, Z.T., Hu, S., Coats, E.R., McDonald, A.G., 2011. Polyhydroxybutyrate synthesis on biodiesel wastewater using mixed microbial consortia. Bioresour. Technol. 102, 3352-3359. doi:10.1016/j.biortech.2010.11.053

Freches, A., Lemos, P.C., 2017. Microbial selection strategies for polyhydroxyalkanoates production from crude glycerol: Effect of OLR and cycle length. N. Biotechnol. 39, Part A, 22-28. doi:10.1016/j.nbt.2017.05.011

Gargalo, C.L., Cheali, P., Posada, J.A., Gernaey, K. V., Sin, G., 2016. Economic Risk Assessment of Early Stage Designs for Glycerol Valorization in Biorefinery Concepts. Ind. Eng. Chem. Res. 55, 6801-6814. doi:10.1021/acs.iecr.5b04593

Janarthanan, O.M., Laycock, B., Montano-Herrera, L., Lu, Y., Arcos-Hernandez, M. V., Werker, A., Pratt, S., 2016. Fluxes in PHA-storing microbial communities during enrichment and biopolymer accumulation processes. N. Biotechnol. 33, 61-72. doi:10.1016/j.nbt.2015.07.007

Jenkins, D., 1992. Towards a comprehensive model of activated sludge bulking and foaming. Water Sci. Technol. 25, 215-230. doi:0273-12231/92

Jiang, Y., Hebly, M., Kleerebezem, R., Muyzer, G., van Loosdrecht, M.C.M., 2011. Metabolic modeling of mixed substrate uptake for polyhydroxyalkanoate (PHA) production. Water Res. 45, 1309-1321. doi:10.1016/j.watres.2010.10.009

Jiang, Y., Marang, L., Tamis, J., van Loosdrecht, M.C.M., Dijkman, H., Kleerebezem, R., 2012. Waste to resource: Converting paper mill wastewater to bioplastic. Water Res. 46, 5517-5530. 
Korkakaki, E., van Loosdrecht, M.C.M., Kleerebezem, R., 2016. Survival of the fastest: Selective removal of the side population for enhanced PHA production in a mixed substrate enrichment. Bioresour. Technol. 216, 1022-1029. doi:10.1016/j.biortech.2016.05.125

Kourmentza, C., Plácido, J., Venetsaneas, N., Burniol-Figols, A., Varrone, C., Gavala, H.N., Reis, M.A.M., 2017. Recent Advances and Challenges towards Sustainable Polyhydroxyalkanoate (PHA) Production. Bioengineering 4, 1-43. doi:10.3390/bioengineering4020055

Lajoie, C.A., Layton, A.C., Gregory, I.R., Sayler, G.S., Taylor, D.E., Meyers, A.J., 2000. Zoogleal Clusters and Sludge Dewatering potential in an Industrial-Sludge wastewater Plant Treatment. Water Environ. Res. 72, 56-64. doi:10.2175/106143000X137112

Laycock, B., Halley, P., Pratt, S., Werker, A., Lant, P., 2014. The chemomechanical properties of microbial polyhydroxyalkanoates. Prog. Polym. Sci. 39, 397-442. doi:10.1016/j.progpolymsci.2013.06.008

Lemos, P.C., Levantesi, C., Serafim, L.S., Rossetti, S., Reis, M.A.M., Tandoi, V., 2008. Microbial

Marang, L., Jiang, Y., Loosdrecht, M.C.M. Van, Kleerebezem, R., 2014. Impact of non-storing biomass on PHA production : An enrichment culture on acetate and methanol. Int. J. Biol. Macromol. 71, 74-80. doi:10.1016/j.ijbiomac.2014.04.051

Marang, L., Jiang, Y., van Loosdrecht, M.C.M., Kleerebezem, R., 2013. Butyrate as preferred substrate for polyhydroxybutyrate production. Bioresour. Technol. 142, 232-239. doi:10.1016/j.biortech.2013.05.031

Martins, A.M.P., Pagilla, K., Heijnen, J.J., Van Loosdrecht, M.C.M., 2004. Filamentous bulking sludge - A critical review. Water Res. 38, 793-817. doi:10.1016/j.watres.2003.11.005

Moita, R., Freches, a., Lemos, P.C., 2014. Crude glycerol as feedstock for polyhydroxyalkanoates production by mixed microbial cultures. Water Res. 58, 9-20. doi:10.1016/j.watres.2014.03.066

Moralejo-Garate, H., Kleerebezem, R., Mosquera-Corral, A., Van Loosdrecht, M.C.M., 2013. Impact of oxygen limitation on glycerol-based biopolymer production by bacterial enrichments. Water Res. 47, 1209-1217. doi:10.1016/j.watres.2012.11.039 community engineering for biopolymer production from glycerol. Appl. Microbiol. Biotechnol. 92, 
Morgan-Sagastume, F., 2016. Characterisation of open, mixed microbial cultures for polyhydroxyalkanoate (PHA) production. Rev. Environ. Sci. Biotechnol. 15, 593-625. doi:10.1007/s11157-016-9411-0

Morgan-Sagastume, F., Hjort, M., Cirne, D., Gérardin, F., Lacroix, S., Gaval, G., Karabegovic, L., Alexandersson, T., Johansson, P., Karlsson, a., Bengtsson, S., Arcos-Hernández, M.V., Magnusson, P., Werker, a., 2015. Integrated production of polyhydroxyalkanoates (PHAs) with municipal wastewater and sludge treatment at pilot scale. Bioresour. Technol. 181, 78-89. doi:10.1016/j.biortech.2015.01.046

Nielsen, P.H., Kragelund, C., Seviour, R.J., Nielsen, J.L., 2009. Identity and ecophysiology of filamentous bacteria in activated sludge. FEMS Microbiol. Rev. 33, 969-998. doi:10.1111/j.15746976.2009.00186.x

Pan, C., Tan, G.A., Ge, L., Chen, C., Wang, J., 2016. Microbial removal of carboxylic acids from 1,3propanediol in glycerol anaerobic digestion effluent by PHAs-producing consortium. Bioechemical Eng. J. 112, 269-276. doi:10.1016/j.bej.2016.04.031

Serafim, L.S., Lemos, P.C., Albuquerque, M.G.E., Reis, M.A.M., 2008. Strategies for PHA production by mixed cultures and renewable waste materials. Appl. Microbiol. Biotechnol. 81, 615-628.

Pardelha, F., Albuquerque, M.G.E., Reis, M.A.M., Dias, J.M.L., Oliveira, R., 2012. Flux balance analysis of mixed microbial cultures: Application to the production of polyhydroxyalkanoates from complex mixtures of volatile fatty acids. J. Biotechnol. 162, 336-345. doi:10.1016/j.jbiotec.2012.08.017 doi:10.1007/s00253-008-1757-y

Serafim, L.S., Lemos, P.C., Rossetti, S., Levantesi, C., Tandoi, V., Reis, M.A.M., 2006. Microbial community analysis with a high PHA storage capacity. Water Sci. Technol. 54, 183-188. doi:10.2166/wst.2006.386

Sheng, G.P., Yu, H.Q., Li, X.Y., 2010. Extracellular polymeric substances (EPS) of microbial aggregates in biological wastewater treatment systems: A review. Biotechnol. Adv. 28, 882-894. doi:10.1016/j.biotechadv.2010.08.001

Tamis, J., Lužkov, K., Jiang, Y., Loosdrecht, M.C.M. van, Kleerebezem, R., 2014. Enrichment of Plasticicumulans acidivorans at pilot-scale for PHA production on industrial wastewater. J. Biotechnol. 192, 161-169. doi:10.1016/j.jbiotec.2014.10.022

Valentino, F., Beccari, M., Fraraccio, S., Zanaroli, G., Majone, M., 2014. Feed frequency in a 

Sequencing Batch Reactor strongly affects the production of polyhydroxyalkanoates (PHAs) from volatile fatty acids. N. Biotechnol. 31, 264-275. doi:10.1016/j.nbt.2013.10.006

Valentino, F., Karabegovic, L., Majone, M., Morgan-Sagastume, F., Werker, A., 2015. Polyhydroxyalkanoate (PHA) storage within a mixed-culture biomass with simultaneous growth as a function of accumulation substrate nitrogen and phosphorus levels. Water Res. 77, 49-63. doi:10.1016/j.watres.2015.03.016

Valentino, F., Morgan-Sagastume, F., Campanari, S., Villano, M., Werker, A., Majone, M., 2016. Carbon recovery from wastewater through bioconversion into biodegradable polymers. $\mathrm{N}$. Biotechnol. 37, 9-23. doi:10.1016/j.nbt.2016.05.007

Varrone, C., Floriotis, G., Heggeset, T.M.B., Le, S.B., Markussen, S., Skiadas, I. V., Gavala, H.N., 2017. Continuous fermentation and kinetic experiments for the conversion of crude glycerol derived from second-generation biodiesel into 1,3-propanediol and butyric acid. Biochem. Eng. J. 128, 149-161. doi:10.1016/j.bej.2017.09.012

Varrone, C., Heggeset, T.M.B., Le, S.B., Haugen, T., Markussen, S., Skiadas, I. V., Gavala, H.N., 2015. Comparison of Different Strategies for Selection/Adaptation of Mixed Microbial Cultures Able to Ferment Crude Glycerol Derived from Second-Generation Biodiesel. Biomed Res. Int. 2015. doi:10.1155/2015/932934

Yang, C., Zhang, W., Liu, R., Zhang, C., Gong, T., Li, Q., Wang, S., Song, C., 2013. Analysis of

Zhu, C., Chiu, S., Nakas, J.P., Nomura, C.T., 2013. Bioplastics from waste glycerol derived from biodiesel industry. J. Appl. Polym. Sci. 130, 1-13. doi:10.1002/app.39157

630 
Table 1. SBR cycle and day of the PHA accumulation tests, SBR cycle characterization and microbial samples analysis. The abbreviation BY_x stands for "PHA accumulation batch at $Y$ concentration $\left(\mathrm{C}_{\mathrm{mm}}\right)$ " where $x$ is the number of the batch test with 12 batches (including the initial) performed in total. The rates and yields were measured only for the batches indicated in bold.

\begin{tabular}{lccc}
\hline $\begin{array}{c}\text { PHA accumulation } \\
\text { test }\end{array}$ & Cycle SBR & $\begin{array}{c}\text { Day } \\
\text { SBR }\end{array}$ & $\begin{array}{c}\text { Microbial samples } \\
\text { analyzed (time 0) }\end{array}$ \\
\hline $\begin{array}{l}\text { (SBR cycle } \\
\text { characterization) }\end{array}$ & 76 & 38 & x \\
B45_initial test & $\mathbf{8 6}$ & 43 & \\
B60_initial test & $\mathbf{8 8}$ & $\mathbf{4 4}$ & \\
B75_initial test & $\mathbf{1 2 0}$ & $\mathbf{6 0}$ & \\
& 126 & 63 & \\
B90_initial test & $\mathbf{1 2 8}$ & $\mathbf{6 4}$ & \\
B90_2 & 232 & 116 & \\
B90_3 & 244 & 122 & \\
B90_4 & $\mathbf{2 4 6}$ & $\mathbf{1 2 3}$ & \\
B90_5 & $\mathbf{2 4 8}$ & $\mathbf{1 2 4}$ & \\
B90_6 & 268 & 134 & \\
B90_7 & 282 & 141 & \\
B90_8 & 284 & 142 & \\
B90_9 & $\mathbf{2 8 6}$ & $\mathbf{1 4 3}$ & \\
(SBR cycle & 298 & 149 & \\
characterization) & $\mathbf{3 0 0}$ & $\mathbf{1 5 0}$ & \\
B90_10 & 312 & 156 & \\
B90_11 & $\mathbf{3 1 4}$ & $\mathbf{1 5 7}$ & \\
B90_12 & & & \\
\hline
\end{tabular}


Table 2. Yields and rates in the SBR cycles 76 and 298.

\begin{tabular}{|c|c|c|c|c|c|c|c|c|c|c|c|c|c|}
\hline & & \multicolumn{5}{|c|}{ Yields } & \multicolumn{2}{|c|}{ Rates } & \multicolumn{3}{|c|}{ Specific rates } & \multirow{2}{*}{ TSS $^{\mathrm{a}}$} & \multirow{2}{*}{$\mathrm{PHA}^{\mathrm{a}}$} \\
\hline & & $Y_{P / S}$ & $Y_{P / S}$ & $Y_{\text {Gly/S }}$ & $Y_{X / S}$ & 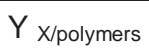 & $-r_{s}$ & $r_{p}$ & $-q_{s}$ & $q_{p}$ & $\mu$ & & \\
\hline & Phase & $\begin{array}{c}\mathrm{C}_{\mathrm{mol}} \mathrm{PHA} / \\
\mathrm{C}_{\mathrm{mol}} \mathrm{S}\end{array}$ & $\begin{array}{l}\text { g COD } \\
\text { PHA/g } \\
\text { COD }_{\text {total }}\end{array}$ & $\begin{array}{c}\mathrm{C}_{\mathrm{mol}} \mathrm{Gly} / \\
\mathrm{C}_{\mathrm{mol}} \mathrm{S}\end{array}$ & $\begin{array}{l}\mathrm{C}_{\text {mol }} \mathrm{X} / \\
\mathrm{C}_{\mathrm{mol}} \mathrm{S}\end{array}$ & $\begin{array}{c}\mathrm{C}_{\text {mol }} \mathrm{X} / \\
\mathrm{C}_{\mathrm{mol}} \\
\mathrm{PHA}+\mathrm{gly}\end{array}$ & $\begin{array}{l}\mathrm{C}_{\mathrm{mM}} \\
\mathrm{S} / \mathrm{h}\end{array}$ & $\begin{array}{c}\mathrm{C}_{\mathrm{mM}} \\
\mathrm{PHA} / \mathrm{h}\end{array}$ & $\begin{array}{l}\mathrm{C}_{\text {mol }} \mathrm{S} / \\
\left(\mathrm{C}_{\text {mol }}\right. \\
\mathrm{X} . \mathrm{h})\end{array}$ & $\begin{array}{l}\mathrm{C}_{\text {mol }} \text { PHA/ } \\
\left(\mathrm{C}_{\text {mol }} \text { X.h) }\right.\end{array}$ & $h^{-1}$ & $g / L$ & $w t \%$ \\
\hline $\begin{array}{c}\text { Cycle } \\
76\end{array}$ & $\begin{array}{c}\text { feast } \\
\text { famine }\end{array}$ & 0.68 & 0.68 & 0.12 & 0.04 & 0.62 & 39.0 & $\begin{array}{l}26.8 \\
-7.1 \\
\end{array}$ & 0.98 & $\begin{array}{r}0.65 \\
-0.19\end{array}$ & 0.11 & 1.83 & 37.3 \\
\hline $\begin{array}{c}\text { Cycle } \\
298\end{array}$ & $\begin{array}{c}\text { feast } \\
\text { famine }\end{array}$ & 0.78 & 0.72 & 0.14 & 0.05 & 0.88 & 34.3 & $\begin{array}{l}27.1 \\
-8.2\end{array}$ & 0.87 & $\begin{array}{c}0.67 \\
-0.23\end{array}$ & 0.16 & 1.88 & 39.0 \\
\hline
\end{tabular}

$\mathrm{Y}_{\mathrm{P} / \mathrm{S}}$ : yield PHA/substrate; $\mathrm{Y}_{\text {Gly/s: }}$ Yield glycogen/substrate; $\mathrm{Y}_{\mathrm{x} / \mathrm{s}}$ : Yield biomass/substrate; $\mathrm{Y}_{\mathrm{x} / \text { polymers }}$ : Yield biomass/polymers (PHA+glycogen). - $r_{s}$ : Substrate consumption rate. $r_{p}$ : PHA formation rate. $q_{p}$ : Specific PHA formation rate.- $q_{s}$ : Specific substrate uptake rate. $\mu$ : Specific growth rate.

a TSS concentration and PHA contents (wt\%) correspond to the end of the feast phase. 
Table 3. Yields and rates from the PHA accumulation experiments with fermentation effluent at increasing initial concentration of VFA.

\begin{tabular}{|c|c|c|c|c|c|c|c|c|c|c|c|c|c|c|}
\hline & & \multicolumn{3}{|c|}{ Yields } & \multicolumn{2}{|c|}{ Rates } & \multicolumn{7}{|c|}{ Specific rates } & \multirow{2}{*}{$\begin{array}{c}\text { Recovered } \\
\text { 1,3-PDO }\end{array}$} \\
\hline & & $\mathrm{Y}_{\mathrm{P} / \mathrm{S}}$ & $\mathrm{Y}_{\mathrm{P} / \mathrm{S}}$ & $Y_{x / s}$ & $-r_{s}$ & $r_{p}$ & $-q_{s}$ & & & $-q_{s}$ & & & $q_{p}$ & \\
\hline \multirow{2}{*}{$\begin{array}{c}\text { Initial VFA } \\
\text { concentration }\end{array}$} & \multirow{2}{*}{ Phase } & \multirow{2}{*}{$\begin{array}{c}\mathrm{C}_{\text {mol }} \mathrm{PHA} / \\
\mathrm{C}_{\text {mol }} \mathrm{S}\end{array}$} & \multirow{2}{*}{$\begin{array}{c}\text { g COD PHA/ } \\
\mathrm{g} \mathrm{COD}_{\text {total }}\end{array}$} & \multirow{2}{*}{$\begin{array}{l}\mathrm{C}_{\text {mol }} \mathrm{X} / \\
\mathrm{C}_{\mathrm{mol}} \mathrm{S}\end{array}$} & \multirow{2}{*}{$\begin{array}{l}\mathrm{C}_{\mathrm{mM}} \\
\mathrm{S} / \mathrm{h}\end{array}$} & \multirow{2}{*}{$\begin{array}{c}\mathrm{C}_{\mathrm{mM}} \\
\mathrm{PHA} / \mathrm{h}\end{array}$} & \multirow{2}{*}{$\begin{array}{c}\mathrm{C}_{\mathrm{mol}} \mathrm{S} /\left(\mathrm{C}_{\mathrm{mol}}\right. \\
\text { X.h) }\end{array}$} & \multicolumn{5}{|c|}{$\mathrm{mol} \mathrm{S} /\left(\mathrm{C}_{\mathrm{mol}} \mathrm{X} . \mathrm{h}\right)$} & \multirow{2}{*}{$\begin{array}{l}\mathrm{C}_{\mathrm{mol}} \mathrm{PHA} \\
/\left(\mathrm{C}_{\mathrm{mol}} \mathrm{X} . \mathrm{h}\right)\end{array}$} & \multirow{2}{*}{$\%$} \\
\hline & & & & & & & & $\mathrm{Ac}$ & Prop & But & Ac+But & Total VFA & & \\
\hline \multirow{3}{*}{$45 \mathrm{C}_{\mathrm{mM}}$} & Overall VFA & 1.00 & 0.82 & 0.04 & 21.8 & $20.2^{\mathrm{a}}$ & 0.71 & & & & & & $0.57^{\mathrm{a}}$ & $100 \%$ \\
\hline & Butyrate & 1.07 & 0.82 & -0.03 & 26.7 & 28.3 & 0.73 & 0.03 & 0.12 & 0.63 & 0.66 & 0.19 & 0.89 & $100 \%$ \\
\hline & Acetate/propionate & 0.71 & 0.84 & 0.34 & 9.2 & 7.7 & 0.50 & 0.06 & 0.22 & & 0.06 & 0.18 & 0.10 & $100 \%$ \\
\hline \multirow{3}{*}{$60 \mathrm{C}_{\mathrm{mM}}$} & Overall VFA & 0.84 & 0.82 & 0.09 & 19.6 & $15.9^{\mathrm{a}}$ & 0.92 & & & & & & $0.50^{\mathrm{a}}$ & $98 \%$ \\
\hline & Butyrate & 0.96 & 0.96 & 0.02 & 24.6 & 23.5 & 0.98 & 0.02 & 0.13 & 0.73 & 0.75 & 0.27 & 0.87 & $99 \%$ \\
\hline & Acetate/propionate & 0.40 & 0.39 & 0.33 & 11.0 & 4.7 & 0.79 & 0.08 & 0.29 & & 0.08 & 0.28 & -0.05 & $98 \%$ \\
\hline \multirow{3}{*}{$75 \mathrm{C}_{\mathrm{mM}}$} & Overall VFA & 0.88 & 0.64 & 0.04 & 19.5 & $16.7^{\mathrm{a}}$ & 0.88 & & & & & & $0.57^{\mathrm{a}}$ & $96 \%$ \\
\hline & Butyrate & 0.97 & 0.78 & -0.04 & 24.5 & 23.8 & 0.72 & 0.02 & 0.13 & 0.73 & 0.75 & 0.18 & 1.00 & $98 \%$ \\
\hline & Acetate/propionate & 0.06 & 0.28 & 0.85 & 9.8 & 4.3 & 1.10 & 0.08 & 0.29 & & 0.08 & 0.38 & -0.23 & $96 \%$ \\
\hline \multirow{3}{*}{$90 \mathrm{C}_{\mathrm{mM}}$} & Overall VFA & 0.81 & 0.66 & 0.05 & 23.2 & $18.4^{\mathrm{a}}$ & 0.85 & & & & & & $0.50^{a}$ & $95 \%$ \\
\hline & Butyrate & 0.91 & 0.75 & -0.01 & 29.7 & 26.8 & 0.91 & 0.03 & 0.13 & 0.69 & 0.71 & 0.25 & 0.87 & $97 \%$ \\
\hline & Acetate/propionate & 0.22 & 0.18 & 0.39 & 10.3 & 2.7 & 0.77 & 0.04 & 0.24 & & 0.04 & 0.26 & -0.17 & $95 \%$ \\
\hline
\end{tabular}

Y p/s: Yield PHA/substrate. Y x/s: Yield biomass/substrate.-rs: Substrate consumption rate. $r_{p}$ : PHA formation rate. qp: Specific PHA formation rate.-qs: Specific substrate uptake rate.

Ac: Acetate. But: Butyrate. Prop: Propionate.

${ }^{a}$ Overall PHA rates for the feast phase were not constant given the two distinctive phases. The number in the table is calculated by dividing the increment in the $\mathrm{C}_{\mathrm{mM}} \mathrm{PHA}$ or $\mathrm{C}_{\mathrm{mM}} \mathrm{PHA} / \mathrm{C}_{\mathrm{mM}} \mathrm{X}$ by the time interval and not with the slope as with the other parameters. 
Table 4. PHA content (wt\%), monomer composition and 1,3-PDO recovery (\%) obtained in the PHA accumulation repeats with fermentation effluent at $90 \mathrm{C}_{\mathrm{mM}}$ initial concentration of VFA.

\begin{tabular}{cccccc}
\hline Batch & $\begin{array}{c}\text { Total } \\
\text { PHA } \\
(\text { wt\% })\end{array}$ & $\begin{array}{c}\text { HB } \\
(\text { wt\% })\end{array}$ & $\begin{array}{c}\text { HV } \\
(\text { wt\% })\end{array}$ & HB:HV ratio & $\begin{array}{c}1,3-P D O \\
\text { recovery } \\
(\%)\end{array}$ \\
\hline B90_2 & 70.7 & 57.1 & 13.5 & $80.9: 19.1$ & 100.0 \\
B90_3 & 74.8 & 61.8 & 13.0 & $82.6: 17.4$ & 94.4 \\
B90_4 & 73.1 & 60.5 & 12.6 & $82.8: 17.2$ & 100.0 \\
B90_5 & 75.9 & 63.7 & 12.1 & $84: 16$ & 98.5 \\
B90_6 & 74.6 & 65.8 & 8.9 & $88.1: 11.9$ & 99.1 \\
B90_7 & 79.4 & 66.8 & 12.5 & $84.1: 15.7$ & 97.8 \\
B90_8 & 78.7 & 66.0 & 12.6 & $83.8: 16$ & 98.7 \\
B90_9 & 81.8 & 67.1 & 14.6 & $82: 17.8$ & 97.2 \\
B90_10 & 78.2 & 65.4 & 12.7 & $83.5: 16.3$ & 99.2 \\
B90_11 & 78.2 & 67.3 & 12.3 & $86: 15.7$ & $107.9^{a}$ \\
B90_12 & 75.7 & 64.2 & 11.4 & $84.8: 15.1$ & 102.4 \\
\hline Av & 76 & 64 & 12 & $84: 16$ & 99 \\
SD & 3.1 & 3.2 & 1.4 & $2.0: 1.8$ & 2.1 \\
\hline
\end{tabular}

${ }^{a}$ Value excluded from the average 
Table 5. Yields and rates from the PHA accumulation repeats with fermentation effluent at $90 \mathrm{C}_{\mathrm{mM}}$ initial concentration of VFA.

\begin{tabular}{|c|c|c|c|c|c|c|c|c|c|c|c|c|c|c|c|c|c|}
\hline \multirow{4}{*}{ Batch } & \multirow{4}{*}{$\begin{array}{l}\text { Duration } \\
\text { (h) }\end{array}$} & \multirow{2}{*}{\multicolumn{2}{|c|}{$\begin{array}{l}\text { Yields } \\
\text { Y P/S } \\
\end{array}$}} & \multicolumn{5}{|c|}{ Rates /productivity } & \multicolumn{3}{|c|}{ Specific rates } & \multirow{4}{*}{$\begin{array}{l}\begin{array}{l}\mathrm{PHA} \\
\mathrm{ini}^{\mathrm{a}}\end{array} \\
\mathrm{wt} \%\end{array}$} & \multirow{4}{*}{$\begin{array}{l}\begin{array}{l}\text { PHA } \\
\text { end }^{b}\end{array} \\
\text { wt\% }\end{array}$} & \multirow{4}{*}{$\begin{array}{c}\begin{array}{l}\mathrm{PHA} \\
\text { end }\end{array} \\
\mathrm{g} / \mathrm{L}\end{array}$} & \multirow{4}{*}{$\begin{array}{c}\begin{array}{c}\text { TSS } \\
\text { ini }^{\mathrm{a}}\end{array} \\
\mathrm{g} / \mathrm{L}\end{array}$} & \multirow{4}{*}{$\begin{array}{c}\text { TSS } \\
\text { end } \\
\text { SBR }^{\mathrm{C}}\end{array}$} & \multirow{4}{*}{$\begin{array}{l}\begin{array}{l}\text { TSS } \\
\text { lost }^{d}\end{array} \\
w t \%\end{array}$} \\
\hline & & & & & & & & $r_{p}$ & $-c$ & & $\mathrm{q}_{\mathrm{p}}$ & & & & & & \\
\hline & & \multirow{2}{*}{$\begin{array}{l}\mathrm{C}_{\text {mol }} \\
\mathrm{PHA} / \\
\mathrm{C}_{\mathrm{mol}} \mathrm{S}\end{array}$} & \multirow{2}{*}{$\begin{array}{l}\text { g COD } \\
\mathrm{PHA} / \mathrm{g} \\
\mathrm{COD}_{\text {total }}\end{array}$} & \multicolumn{4}{|c|}{$\mathrm{C}_{\mathrm{mM}} \mathrm{S} / \mathrm{h}$} & \multirow{2}{*}{$\begin{array}{c}\mathrm{C}_{\mathrm{mM}} \\
\mathrm{PHA} / \mathrm{h}\end{array}$} & \multicolumn{2}{|c|}{$\mathrm{C}_{\mathrm{mol}} \mathrm{S} /\left(\mathrm{C}_{\mathrm{mol}} \mathrm{X} . \mathrm{h}\right)$} & \multirow{2}{*}{$\begin{array}{c}\mathrm{C}_{\mathrm{mol}} \mathrm{PHA} \\
/\left(\mathrm{C}_{\mathrm{mol}} \mathrm{X} . \mathrm{h}\right)\end{array}$} & & & & & & \\
\hline & & & & Overall & $A c$ & Prop & But & & Overall & But & & & & & & & \\
\hline $\begin{array}{c}\text { B90_initial } \\
\text { test }\end{array}$ & 3 & 0.91 & 0.75 & 29.7 & 0.86 & 4.2 & 21.6 & 26.8 & 0.91 & 0.69 & 0.87 & 4.4 & 69.9 & 1.73 & 0.77 & 1.35 & $8 \%$ \\
\hline B90_4 & 3 & 0.99 & 0.78 & 21.7 & 0.11 & 2.8 & 18.5 & 21.4 & 0.95 & 0.83 & 1.03 & 2.6 & 73.1 & 1.36 & 0.53 & & \\
\hline B90_5 & 3 & 0.99 & 0.88 & 21.8 & 0.08 & 2.7 & 18.8 & 21.2 & 1.00 & 0.92 & 1.18 & 2.3 & 75.9 & 1.36 & 0.49 & & \\
\hline B90_9 & 5 & 1.02 & 0.88 & 16.2 & 0.35 & 2.3 & 13.0 & 16.3 & 0.89 & 0.75 & 1.08 & 1.8 & 81.8 & 1.69 & 0.43 & 1.76 & $57 \%$ \\
\hline B90_10 & 4 & 1.08 & 0.82 & 16.6 & 0.01 & 2.0 & 14.0 & 17.5 & 0.85 & 0.83 & 1.13 & 1.6 & 82.4 & 1.52 & 0.39 & 1.46 & $57 \%$ \\
\hline B90_12 & 3.5 & 0.89 & 0.84 & 22.5 & 0.73 & 3.4 & 17.4 & 20.5 & 1.23 & 0.94 & 1.21 & 1.8 & 75.7 & 1.48 & 0.45 & 1.73 & $42 \%$ \\
\hline \multirow{2}{*}{$\begin{array}{l}\text { Average } \\
\text { repeats }\end{array}$} & $A v$ & 0.99 & 0.84 & 19.8 & 0.22 & 2.6 & 16.3 & 19.4 & 0.98 & 0.85 & 1.13 & & & 1.48 & 0.46 & & \\
\hline & SD & 0.07 & 0.04 & 3.1 & 0.33 & 0.5 & 2.7 & 2.3 & 0.15 & 0.08 & 0.07 & & & 0.14 & 0.05 & & \\
\hline
\end{tabular}

${ }^{\mathrm{a}}$ at the beginning of the PHA accumulation; ${ }^{\mathrm{b}}$ at the end of the butyrate phase in the PHA accumulation; ${ }^{\mathrm{c}}$ at the end of the SBR used as inoculum; ${ }^{\mathrm{a}}$ lost during the sedimentation step between the SBR and the PHA accumulation

Y p/s: Yield PHA/substrate..- $r_{s}$ : Substrate consumption rate. $r_{p}$ : PHA formation rate. $q_{p}$ : Specific PHA formation rate.- $q_{s}$ : Specific substrate uptake rate. Ac: Acetate. But: Butyrate. Prop: Propionate. 


\section{Figure captions}

Fig. 1. Strategy for production of PHA from volatile fatty acids and recovery of 1,3-propanediol from fermented crude glycerol. (CSTR: Continuous Stirred Tank Reactor, SBR: Sequential Batch Reactor).

Fig. 2. Evolution of the SBR enrichment reactor. A: Duration of feast phase (determined by $\mathrm{pO}_{2}$ saturation). B: Polymer and monomer content in the cells ( $\mathrm{g} / 100 \mathrm{~g}$ TSS) at the end of the feast phase.

Fig. 3. Characterization of cycle 76 of the enrichment reactor (SBR). A: Profile of oxygen saturation. B Concentration of substrates $\left(\mathrm{C}_{\mathrm{mM}}\right)$ and $\mathrm{N}-\mathrm{NH}_{3}\left(\mathrm{~N}_{\mathrm{mM}}\right)$. C: Concentration of products $\left(\mathrm{C}_{\mathrm{mM}}\right)$. D: Polymer and monomer content in the cells $(\mathrm{g}$ /100 g TSS).

Fig. 4. Relative abundance of the predominant bacterial genera identified by $16 \mathrm{~S}$ rRNA gene sequencing at different cycles of the SBR $(>1 \%$ in at least one of the samples). Numbers within the bars indicate the relative abundance of the correspondent genus. Numbers on top of the bars indicate the summed abundance of OTUs classified as the genera Thauera and Amaricoccus.

Fig. 5. PHA accumulation experiments with crude glycerol fermentation effluent at increasing initial concentration of VFA. Each experiment corresponds to a column of graphs. A: Profile of oxygen saturation. B: 1,3-PDO concentration $\left(\mathrm{C}_{\mathrm{mm}}\right)$ and undefined COD $(\mathrm{mg} / \mathrm{L})$. C: Concentration of substrates $\left(\mathrm{C}_{\mathrm{mM}}\right)$ and $\mathrm{N}-\mathrm{NH}_{3}\left(\mathrm{~N}_{\mathrm{mM}}\right)$. D: Concentration of products $\left(\mathrm{C}_{\mathrm{mM}}\right)$. E: Polymer and monomer content in the cells (g/100 g TSS). *Undefined COD refers to the difference between the COD measured in the supernatant and the sum of theoretical COD of metabolites measured by HPLC.

Fig. 6. Comparison of calculated parameters from the PHA accumulation experiments with crude glycerol fermentation effluent at increasing initial concentration of VFA. A: Maximum PHA content inside the cells ( $\mathrm{g}$ polymer/100 g TSS). B: Maximum PHA (g/L). C: YP/S (Yield PHA/substrate). D: Specific substrate consumption rate. E: Specific PHA formation rate. For all graphs, values for the overall batch (black circle $\bullet$ ) and for the butyrate phase (green triangle $\boldsymbol{\Delta}$ ) are presented.

Fig. 7. COD Balance of the process with influents indicated in red and effluents in green. Values next to the compounds indicate the $\mathrm{g}$ COD consumed or produced for one PHA batch accumulation $\left(90 \mathrm{C}_{\mathrm{mm}}\right)(A)$ and mass fraction of each component referring to the total COD input (g COD/g COD input) (B). For the PHA and 1,3-PDO streams, two sets of values are indicated separated by a bar, corresponding to values obtained after the butyrate phase or after depletion of all VFA. The term "Others soluble" refers to soluble COD excluding glycerol, 1,3-PDO, butyrate, acetate and propionate, thus contemplating mostly undefined COD present in the crude glycerol. 
Figure 1 Crude glycerol fermentation

PHA accumulation

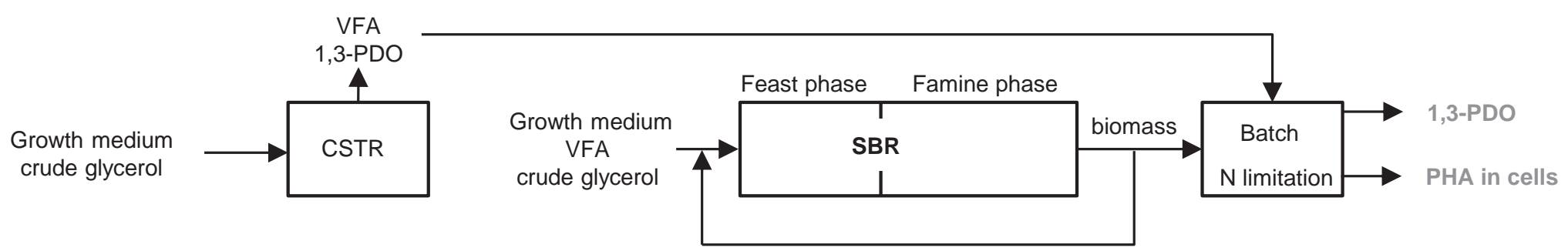




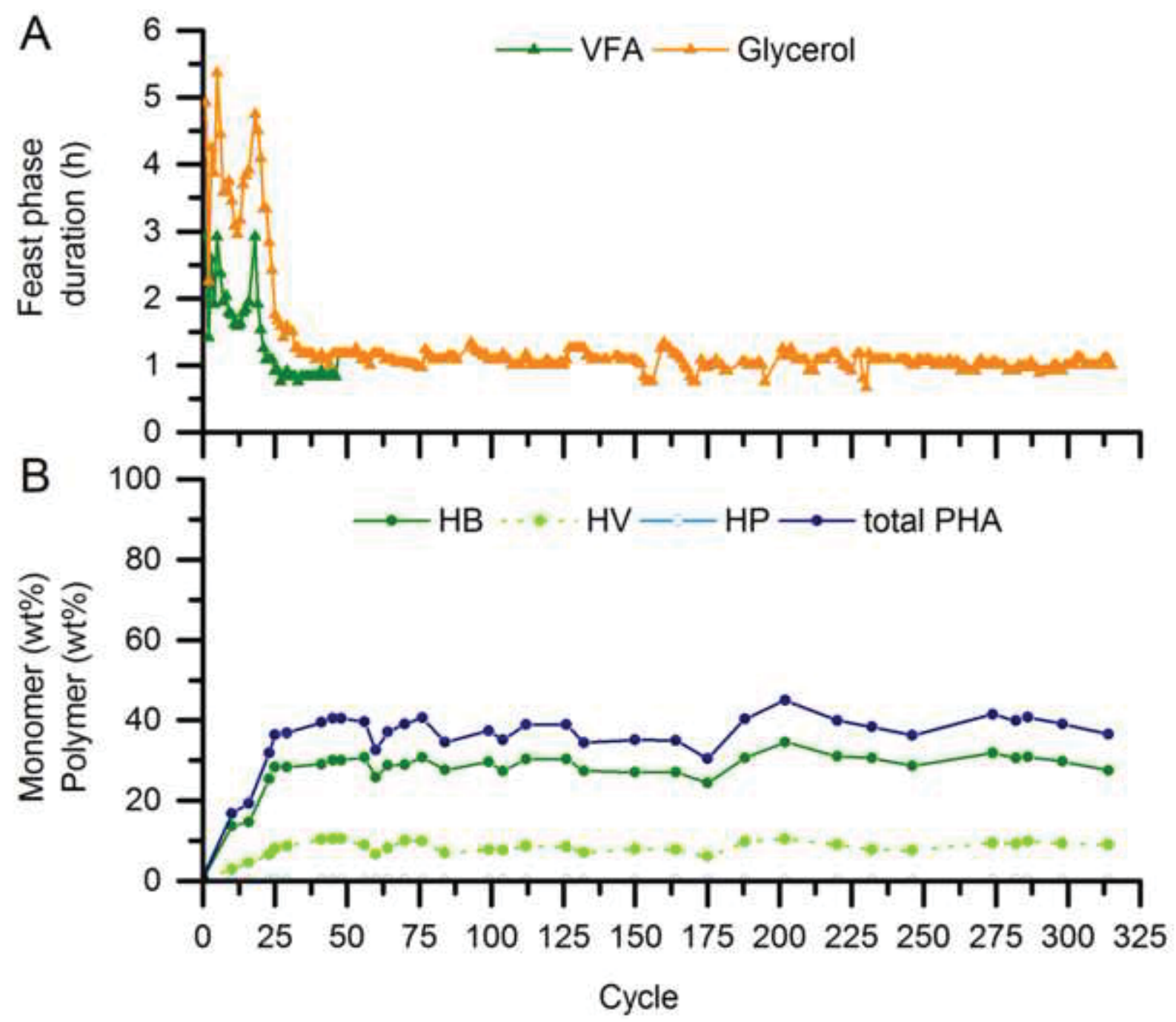


Click here to download high resolution image

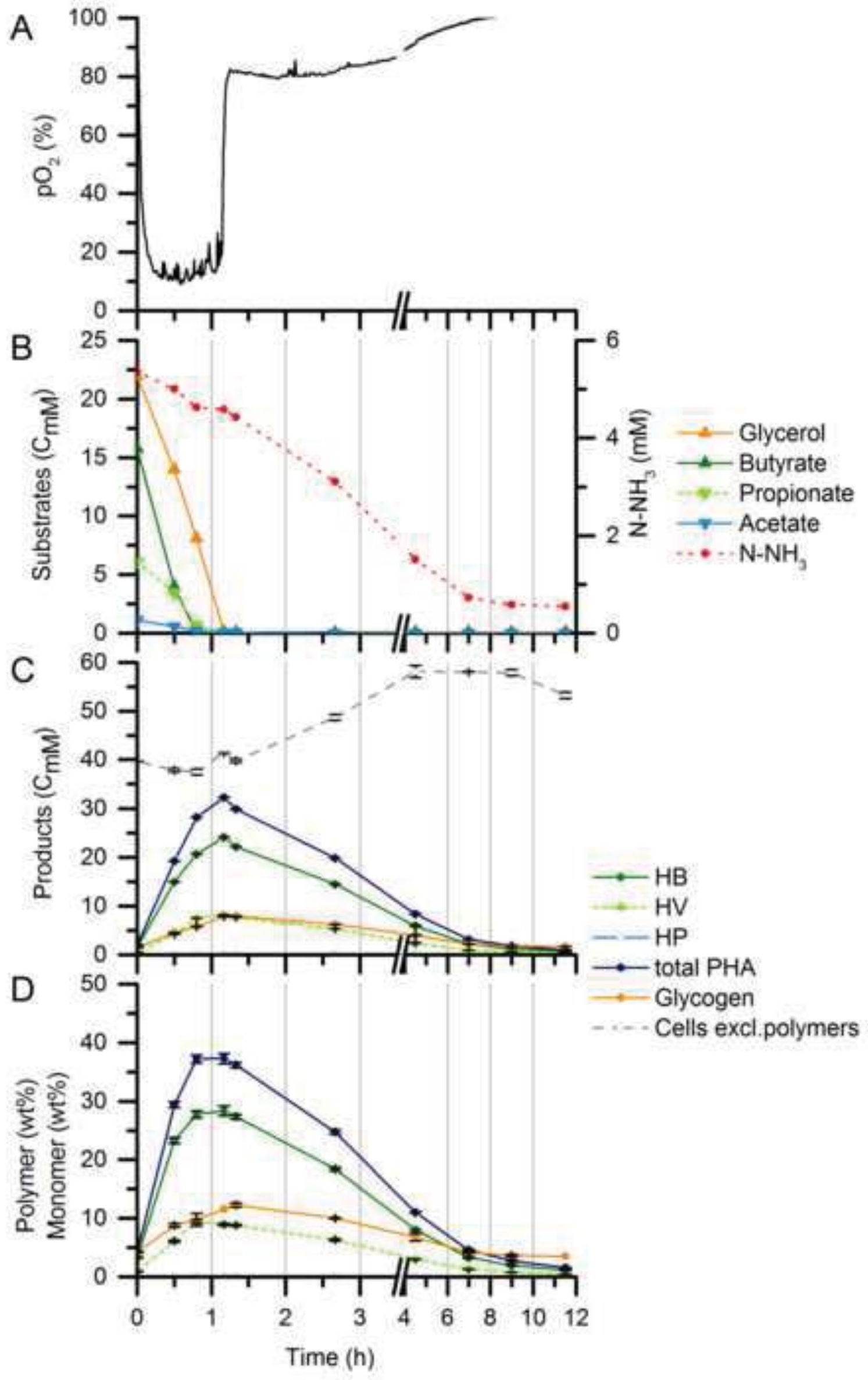




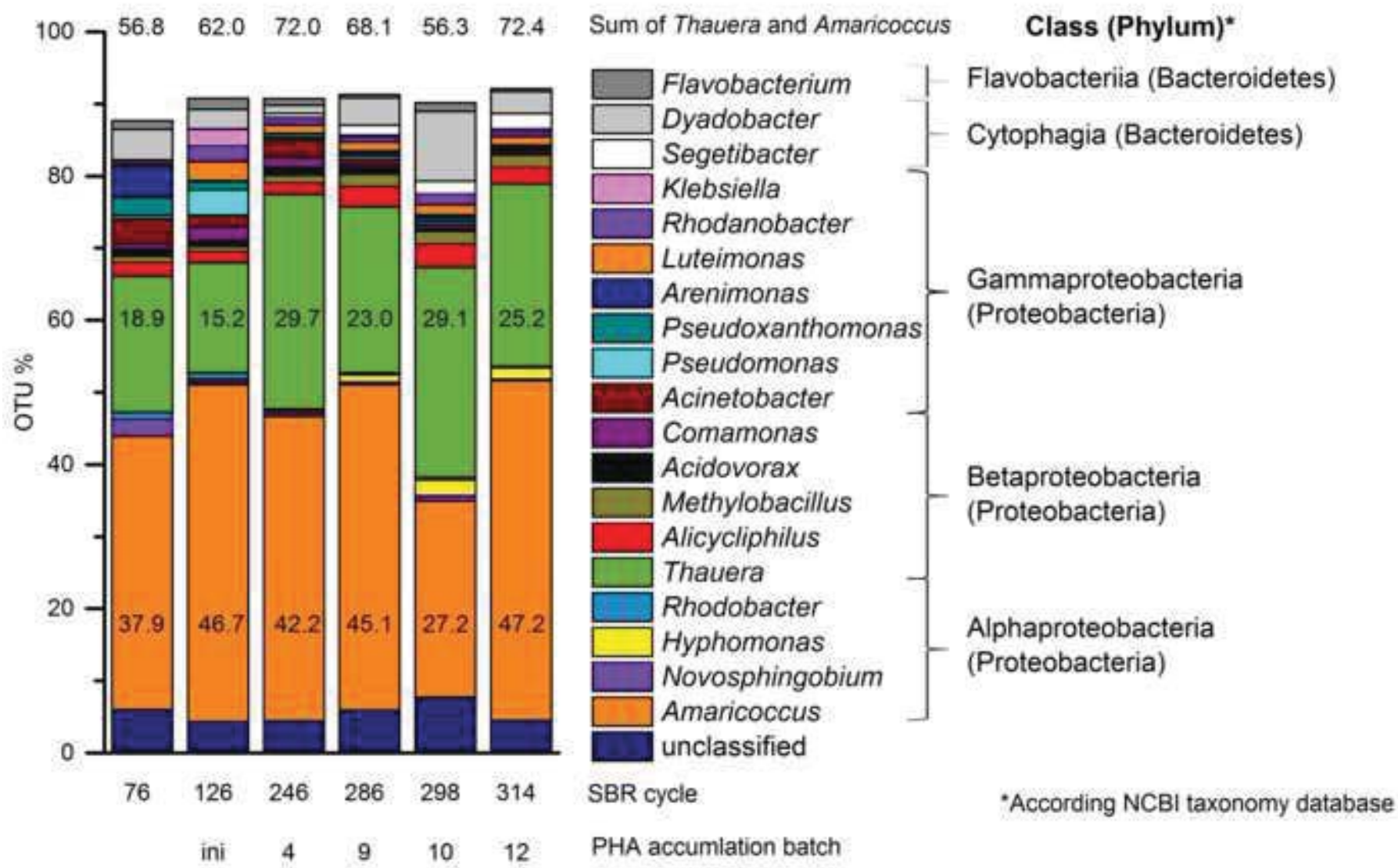




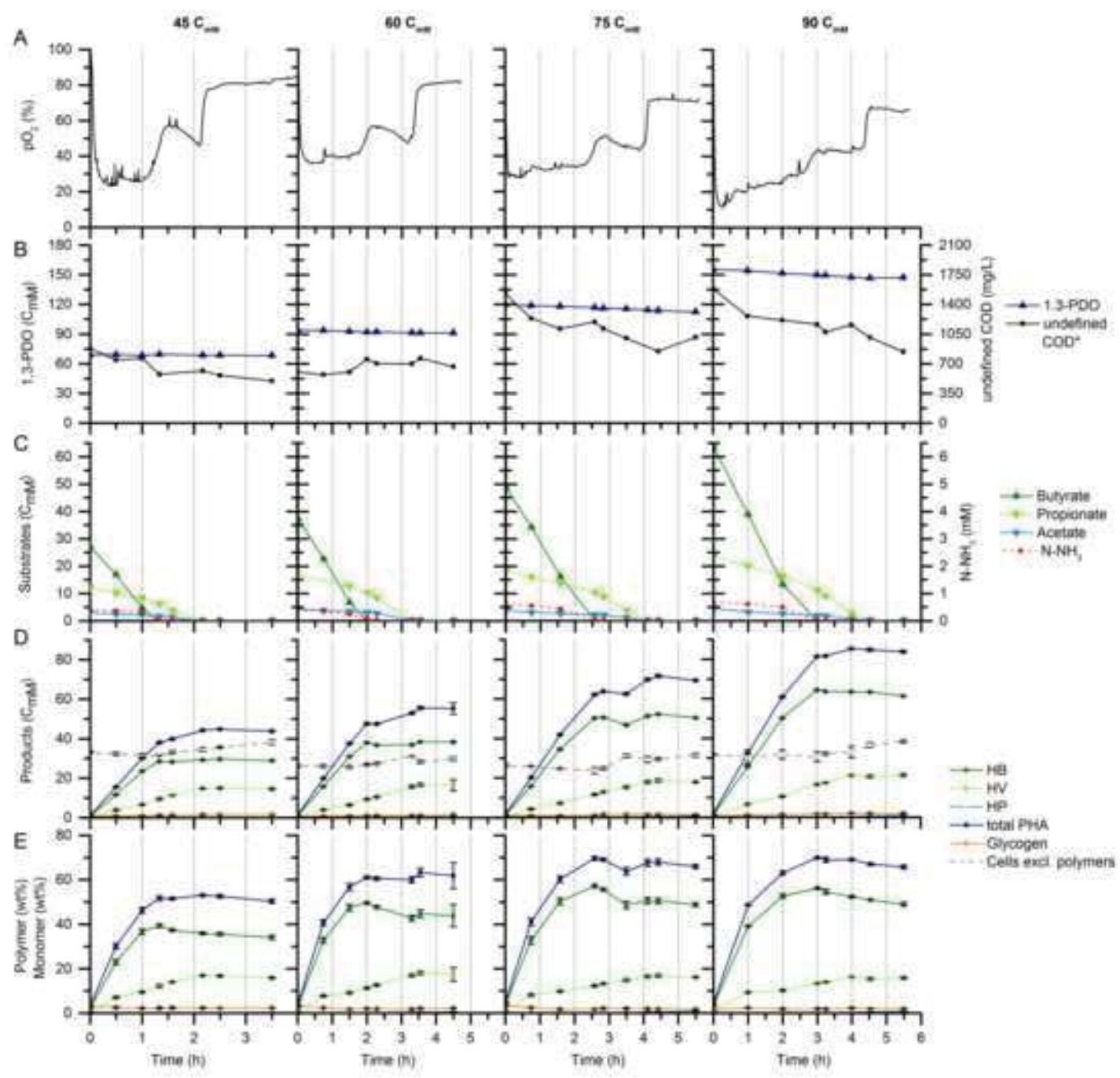



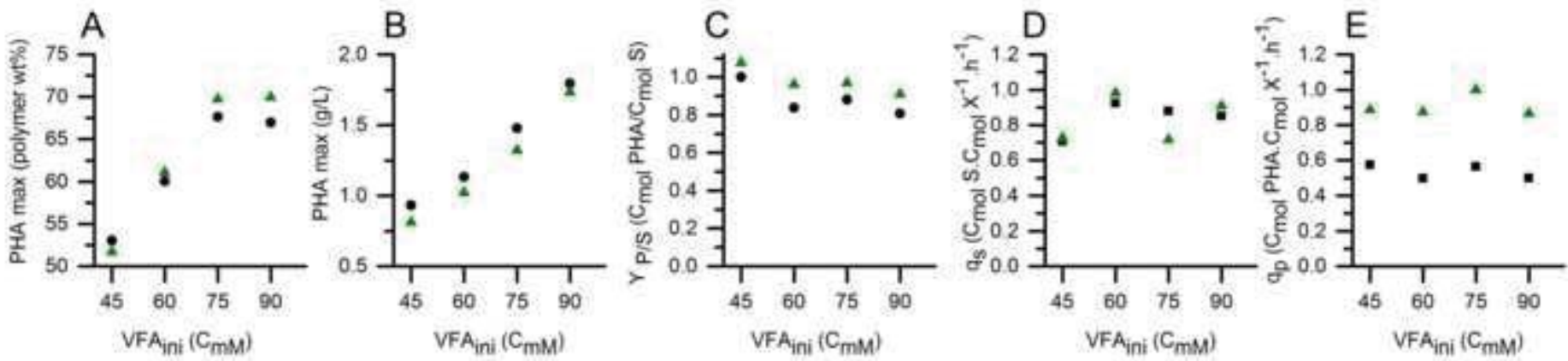
Figure 7

A
Clarified effluent

CSTR

1,3-PDO 11.18

Butyrate 4.33

Propionate 1.81

Acetate 0.30

Glycerol $<0.02$

Others soluble 3.19

Effluent SBR

Cells excl. polymers 2.03

PHA 0.01

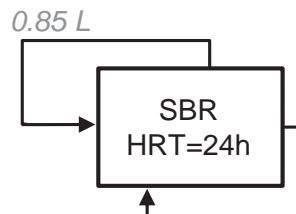

$\uparrow$

$0.85 \mathrm{~L}$

Influent SBR

Glycerol 1.40

Others soluble 0.25

Synthetic VFA 1.49

Glycerol 19.58

Others soluble 3.24

B

Glycogen 0.07

Others soluble 0.09

$0.85 L$
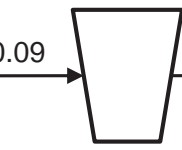

PHA 0.01

Glycogen 0.04

Others soluble 0.02

Settlement

$0.65 L$

$0.2 L$

Supernatant sedimentation

Cells excl. polymers 1.02

PHA 0.01

Glycogen 0.04

Others soluble 0.07
1,3-PDO stream

1,3-PDO 10.95/10.57

Propionate 1.19/0

Acetate $0.25 / 0$

Others soluble 2.09/1.96

PHA

accumulation
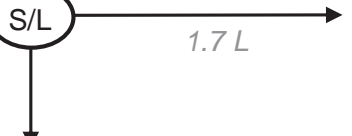

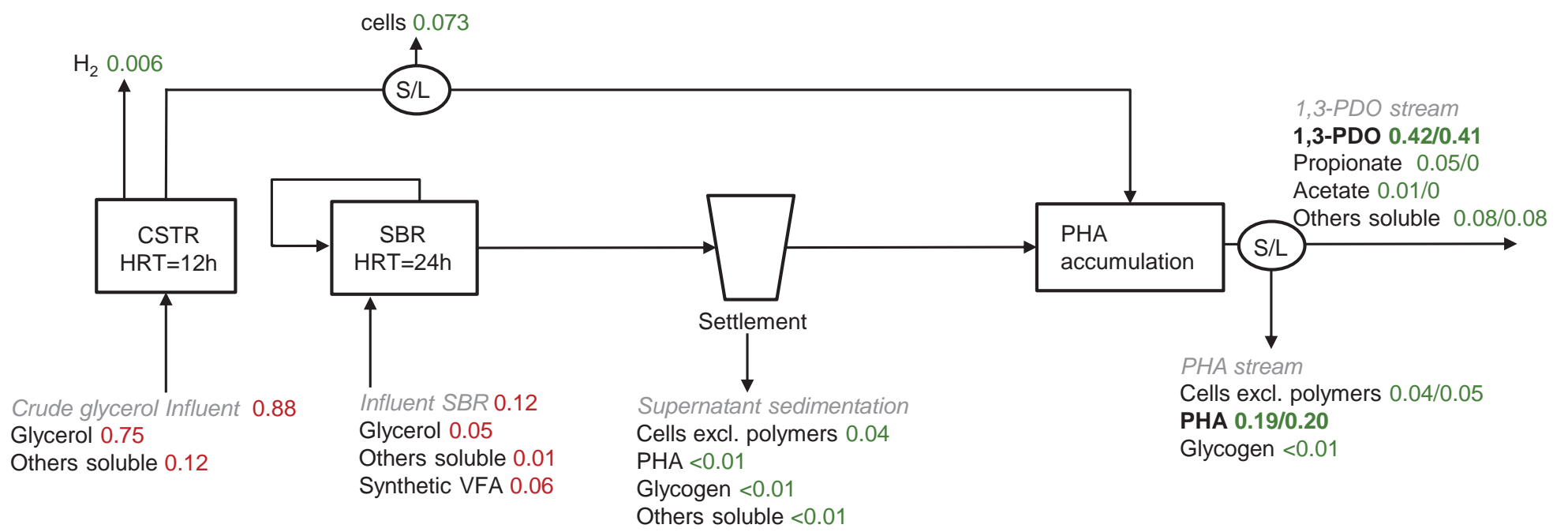


